\title{
Calcium-Calmodulin-Dependent Kinase II Modulates Kv4.2 Channel Expression and Upregulates Neuronal A-Type Potassium Currents
}

\author{
Andrew W. Varga, ${ }^{\star}$ Li-Lian Yuan, ${ }^{\star}$ Anne E. Anderson, Laura A. Schrader, Gang-Yi Wu, Jennifer R. Gatchel, \\ Daniel Johnston, and J. David Sweatt \\ Division of Neuroscience, Baylor College of Medicine, Houston, Texas 77030
}

\begin{abstract}
Calcium-calmodulin-dependent kinase II (CaMKII) has a long history of involvement in synaptic plasticity, yet little focus has been given to potassium channels as CaMKII targets despite their importance in repolarizing EPSPs and action potentials and regulating neuronal membrane excitability. We now show that Kv4.2 acts as a substrate for CaMKII in vitro and have identified CaMKII phosphorylation sites as Ser438 and Ser459. To test whether CaMKII phosphorylation of Kv4.2 affects channel biophysics, we expressed wild-type or mutant Kv4.2 and the $\mathrm{K}^{+}$channel interacting protein, KChIP3, with or without a constitutively active form of CaMKII in Xenopus oocytes and measured the voltage dependence of activation and inactivation in each of these conditions. CaMKII phosphorylation had no effect on channel biophysical properties. However, we found that levels of Kv4.2 protein are increased with CaMKII phosphorylation in transfected COS cells, an effect attributable to direct channel phosphorylation based on site-directed mutagenesis studies. We also obtained corroborating physiological data showing increased surface A-type channel expression as revealed by increases in peak $\mathrm{K}^{+}$current amplitudes with CaMKII phosphorylation. Furthermore, endogenous A-currents in hippocampal pyramidal neurons were increased in amplitude after introduction of constitutively active CaMKII, which results in a decrease in neuronal excitability in response to current injections. Thus CaMKII can directly modulate neuronal excitability by increasing cell-surface expression of A-type $\mathrm{K}^{+}$channels.
\end{abstract}

Key words: kinase; hippocampus; phosphorylation; potassium channel; synaptic plasticity; memory

\section{Introduction}

Calcium-calmodulin-dependent kinase type II (CaMKII) is an abundant neuronal protein that has received much attention for its key role in long-term potentiation (LTP), a cellular substrate for learning. A feature of CaMKII that originally made it an attractive candidate to mediate the synaptic processes underlying learning is that when CaMKII is activated by a $\mathrm{Ca}^{2+}-$ calmodulin complex, it can be autophosphorylated at Thr286, and this event renders the kinase autonomously active and less sensitive to additional increases in calcium (Hanson et al., 1989). Thus, CaMKII can translate a transient event (influx of $\mathrm{Ca}^{2+}$ ) into a long-lasting change independent of that transient event (autophosphorylation and enzyme activation).

Moreover, CaMKII has been shown to be necessary and sufficient for LTP induction and necessary for various learning para-

\footnotetext{
Received Sept. 10, 2003; revised Feb. 17, 2004; accepted Feb. 18, 2004.

This work was supported by National Institute of Neurological Disorders and Stroke Program Project Grant NS 37444 (J.D.S., D.J.) and National Institute on Drug Abuse predoctoral National Research Service Award Grant DA 15163 (A.W.V.). We thank Drs. Coleen Atkins and Tom Soderling for generously providing the CaMKII $\Delta 316$ construct and Dr. Roberto Malinow for generously providing the tCaMKII construct. We thank Dr. Jim Trimmer for providing the Kv4.2 monoclonal antibody, Dr. Rick Gray for writing the data acquisition software, and Vikas Kumar, Dr. Michael Levy, and Dr. Shari Birnbaum for expert technical assistance.

${ }^{*}$ A.W.V. and L.-L.Y. contributed equally to this work.

Correspondence should be addressed to J. David Sweatt, Division of Neuroscience, S607, One Baylor Plaza, Houston, TX 77030. E-mail: jsweatt@bcm.tmc.edu.

DOI:10.1523/JNEUROSCI.0154-04.2004

Copyright $\odot 2004$ Society for Neuroscience $\quad$ 0270-6474/04/243643-12\$15.00/0
}

digms (Malenka et al., 1989; Malinow et al., 1989; Silva et al., 1992a,b; Pettit et al., 1994; Lledo et al., 1995; Wang and Kelly, 1995; Giese et al., 1998; Hinds et al., 1998). Studies assessing the downstream targets of CaMKII have justifiably focused on glutamate receptor subunits, because they are principally responsible for excitatory neurotransmission in the CNS and play an important role in LTP expression. There are many other potential substrates for CaMKII phosphorylation in the dendritic membrane, however.

In particular, A-type potassium channels, specifically the Kv4.2 subunit, are expressed at high density on dendrites of hippocampal pyramidal neurons (Sheng et al., 1992; Maletic-Savatic et al., 1995; Hoffman et al., 1997). The Shal family of channels, of which Kv4.2 is a member, comprises four $\alpha$ subunit monomers that tetramerize to form the channel (Choe et al., 1999). The Kv4.2 $\alpha$ subunit can be modulated by interacting partners including $\mathrm{Kv} \beta$ subunits, $\mathrm{K}^{+}$channel interacting proteins (KChIPs), and dipeptidyl peptidase IV-related protein (Nakahira et al., 1996; Perez-Garcia et al., 1999; An et al., 2000; Holmqvist et al., 2002; Nadal et al., 2003). Modulation of Kv4.2 is not limited to protein-protein interactions; Kv4.2 has been shown to be a bona fide substrate for phosphorylation by extracellular signalregulated kinase (ERK)-mitogen-activated protein kinase (MAPK) and PKA (Adams et al., 2000; Anderson et al., 2000). These post-translational modifications have been shown to change both current density and biophysical properties of A-type 
potassium currents thought to be mediated by Kv4.2 (Hoffman and Johnston, 1998; Yuan et al., 2002). This is significant, because A-type potassium channels are important for regulating the excitability of neurons, and furthermore, dendritic A-type potassium channels have been implicated in both the induction and expression of LTP (Watanabe et al., 2002).

Because CaMKII is so crucial to memory formation and because Kv4.2 seems to be a viable phosphorylation target based on its function and localization, this study sought to determine whether Kv4.2 acts as a substrate for CaMKII, and if so, what the functional consequence of such phosphorylation might be. Here we present evidence that CaMKII phosphorylates the $\mathrm{C}$ terminus of Kv4.2 at Ser438 and Ser459. These phosphorylation events on the native channel in the cell result in an increase in total cellular Kv4.2 assessed biochemically. We obtained corroborating physiological data showing that active CaMKII or CaMKII site aspartate point mutants increased surface A-type channel expression as revealed by increases in peak $\mathrm{K}^{+}$current amplitudes. The change in peak current amplitude was unaccompanied by changes in the biophysical parameters of Kv4.2-mediated A-current. Finally, we demonstrated that constitutively active CaMKII activity can potentiate native A-currents in hippocampal neurons.

\section{Materials and Methods}

Protein expression and purification. The Kv4.2 N-terminal and C-terminal domain proteins were expressed in Escherichia coli as glutathione $S$-transferase (GST) fusion proteins using methods modified from Hakes and Dixon (1992) and Anderson et al. (2000). Plasmids containing the N-terminal (amino acid residues 1-133) and C-terminal (amino acid residues 411-630) domain cDNAs were constructed using the GST-fusion vector pGEX-KN (Hakes and Dixon, 1992). A single colony of BL21(DE3)-pLysS cells transformed with the protein plasmid was grown in Luria broth [LB $(170 \mathrm{~mm} \mathrm{NaCl}, \mathrm{pH} 7.5,1 \%$ tryptone, and $0.5 \%$ yeast extract)] containing $20 \mu \mathrm{g} / \mathrm{ml}$ carbenicillin and then used to seed a $500 \mathrm{ml}$ culture. After growing to an optical density of $0.6-0.8$ $\left(\mathrm{A}_{600}\right)$, the culture was centrifuged for $15 \mathrm{~min}$ at $1000 \times g\left(\right.$ and $\left.4^{\circ} \mathrm{C}\right)$ using a Beckman Centrifuge Model J2-21M (Beckman Instruments, Fullerton, CA). The cell pellet was resuspended in $500 \mathrm{ml}$ of LB with carbenicillin. The bacteria was induced by incubation at room temperature (RT) with $200 \mu \mathrm{M}$ isopropyl $\beta$-D-thiogalactopyranoside for $4 \mathrm{hr}$ and harvested by centrifugation.

The cells were resuspended and incubated in Tris buffer $1(50 \mathrm{~mm}$ Tris- $\mathrm{HCl}$, pH 8.0, 2 mm EDTA, $10 \mathrm{mg} / \mathrm{ml}$ pepstatin, $10 \mu \mathrm{g} / \mathrm{ml}$ leupeptin, and $100 \mu \mathrm{M}$ PMSF) containing $10 \mathrm{~mm} \beta$-mercaptoethanol and $100 \mu \mathrm{g} / \mathrm{ml}$ lysozyme (Sigma, St. Louis, MO) for $15 \mathrm{~min}$ at $30^{\circ} \mathrm{C}$. After solubilization with $1.5 \% N$-laurylsarcosine, the lysate was incubated with $20 \mu \mathrm{g} / \mathrm{ml}$ DNase I (Boehringer Mannheim, Indianapolis, IN) and $10 \mathrm{~mm} \mathrm{MgCl}$. The lysate was then centrifuged for $15 \mathrm{~min}$ at $1000 \times \mathrm{g}$ (and $4^{\circ} \mathrm{C}$ ) (RT 6000B; Sorvall, Newtown, CT) and adjusted to a $2 \%$ Triton X-100 concentration.

The GST-fusion protein was purified using glutathione affinity absorption. Glutathione agarose beads were washed, resuspended in Tris buffer 1 , and then incubated with the lysate for $1 \mathrm{hr}$ at $4^{\circ} \mathrm{C}$. The beads are washed three times with Tris buffer 1 by repeated centrifugation $(100 \times$ $g$ for $5 \mathrm{~min}$ at $4^{\circ} \mathrm{C}$; Sorvall). After the final wash, the bead preparation was resuspended in Tris buffer 2 (20 mm Tris- $\mathrm{HCl}, \mathrm{pH} 7.5,0.5 \mathrm{~mm}$ EDTA, 0.5 mM EGTA, $1 \mathrm{~mm} \mathrm{Na}_{4} \mathrm{P}_{2} \mathrm{O}_{7}, 10 \mu \mathrm{g} / \mathrm{ml}$ aprotinin, and $10 \mu \mathrm{g} / \mathrm{ml}$ leupeptin).

Phosphorylation of Kv4.2 N-terminal and C-terminal GST fusion proteins. Kv4.2 N-terminal or C-terminal GST-fusion proteins were incubated at $37^{\circ} \mathrm{C}$ in reaction mixtures $(25 \mu \mathrm{l})$ containing $70 \mathrm{ng}$ of the catalytic subunit of CaMKII, Tris buffer 2, and ATP mix 1 (100 $\mu \mathrm{M}$ ATP, 100 $\mathrm{mM} \mathrm{MgCl}_{2}$, and $10 \mu \mathrm{Ci}$ of $\left.\left[\gamma^{-32} \mathrm{P}\right] \mathrm{ATP}\right)$. Reactions were stopped by boiling for 5 min with sample buffer $(30 \mathrm{~mm}$ Tris-HCl, pH 6.8, $200 \mathrm{~mm}$ DTT, $40 \%$ glycerol, $8 \%$ SDS, and $0.04 \mathrm{mg} / \mathrm{ml}$ bromophenol blue). The GST-fusion proteins were separated by SDS-PAGE (10\%) and visualized by Coomassie blue staining. Phosphopeptides were identified by autoradiography. As a control, parallel reactions were performed for GST with and without the kinases and ATP mix 1. A time course of kinase phosphorylation was also performed to ensure a maximal extent of phosphorylation.

Phosphopeptide mapping. Phosphorylation reactions were performed as described above with some modifications; a preparative scale (reaction volume of $300-400 \mu \mathrm{l}$ ) of the reaction was used. The incubation period was adjusted, based on the time course of kinase phosphorylation of the fusion proteins. The phosphorylated GST-fusion protein was separated by SDS-PAGE (10\%). After Coomassie blue staining of the gels, the bands corresponding to the N-terminal or C-terminal fusion proteins were excised, and an in-gel digestion with trypsin or Lys-C was performed as described previously, with minor modifications (Frangioni and Neel, 1993; Anderson et al., 2000). After extraction from the gel, the peptides were separated using reverse-phase HPLC with absorption monitoring at 214,254 , and $280 \mathrm{~nm}$. Counts per minute in each HPLC fraction were measured as Cherenkov radiation. Phosphopeptides identified as HPLC fractions containing high radioactivity were applied to Sequelon arylamine membranes (Millipore, Bedford, MA) essentially as described by the manufacturer. After drying, the membrane was rinsed two times sequentially with $10 \mathrm{ml}$ of methanol, with water, and finally with $5 \mathrm{ml}$ of $10 \%$ trifluoroacetic acid and $50 \%$ acetonitrile in water. The membrane was air-dried, cut into pieces with a scalpel blade, inserted in a BLOTT cartridge, and sequenced in an Applied Biosystems (Foster City, CA) model 477A Protein Sequencer with an in-line 120A PTHAnalyzer using optimized cycles. Instead of butyl chloride, $90 \%$ methanol containing phosphoric acid $(15 \mu \mathrm{l} / 100 \mathrm{ml})$ was used to extract the cleaved amino acids. After conversion, $50 \%$ of the sample was transferred to the HPLC for PTH-amino acid identification, and the other $50 \%$ was collected in the instrument fraction collector for determination of radioactivity by scintillation counting.

DNA preparation and site-directed mutagenesis. The original Kv4.2 cDNA was kindly provided by Dr. Paul Pfaffinger (Baylor College of Medicine, Houston, TX)and subsequently subcloned into a pCI:Neo vector (Promega, Madison, WI) containing a cytomegalovirus promoter. Point mutations were made using a site-directed mutagenesis kit (Stratagene, La Jolla, CA). The primers used included 5'-AGGATACGGGCAGCCAAAGCAGGAAGTGCAAATGCCTAC-3' for S438A, 5' AGGATACGGGCAGCCAAAGATGGAAGTGCAAATGCCTAC-3' for S438D, 5'-AGCAACCAACTACAAGCCTCGGAGGATGAACC-3' for S459A, and 5'-AGCAACCAACTACAAGACTCGGAGGATGAACC-3' for S459D. Mutations were confirmed by restriction enzyme digest and DNA sequencing (Seqwright, Houston, TX). In all cases, the entire Kv4.2 region was sequenced to determine whether any nonspecific mutations were introduced.

COS-7 and Chinese hamster ovary cell transfection and protein harvest. The FuGene 6 transfection reagent was used for COS-7 cell transfections with plasmid DNAs of wild-type or mutant $\mathrm{Kv} 4.2, \mathrm{~K}^{+}$channel interacting proteins (KChIP3), and constitutively active CaMKII or green fluorescent protein (GFP) as a control (1:1:0.2 $\mu \mathrm{g}$ ratio). COS-7 cells were grown on $35 \mathrm{~mm}$ plates to a $4 \times 10^{5}$ cell density. Each plate received $3 \mu \mathrm{l}$ of FuGene 6 reagent and $2 \mu \mathrm{g}$ of total DNA per the FuGene instruction manual. Eighteen to $30 \mathrm{hr}$ after transfection, COS cells were scraped in $1 \mathrm{ml}$ of homogenization buffer (HB) per dish (20 mm Tris-HCl, pH 7.5, $1 \mathrm{~mm}$ EGTA, 1 mM EDTA), containing $200 \mu \mathrm{M}$ phenylmethylsulfonyl fluoride, 4 mm para-nitrophenylphosphate, $1 \mathrm{~mm}$ sodium orthovanadate, and a 1:100 dilution of protease inhibitor mixture (P-8340; Sigma) [80 $\mu \mathrm{M}$ aprotonin, $2.1 \mathrm{~mm}$ leupeptin, $104 \mathrm{~mm}$ 4-(2-aminoethyl)benzenesulfonyl fluoride, 3.6 mm bestatin, $1.5 \mathrm{~mm}$ pepstatin A, and $1.4 \mathrm{~mm}$ E-64]. These harvested cells were then centrifuged at $15,000 \times g(10,000 \mathrm{rpm}$ in a Hermle Labnet Eppendorf tube centrifuge) at $4^{\circ} \mathrm{C}$ for $5 \mathrm{~min}$. The supernatant was removed, and each cell pellet was resuspended in $300 \mu \mathrm{l}$ of $\mathrm{HB}$ followed by sonication [10 pulses at output level 1.5 on a Branson (Danbury, CT) Sonifier 250] to lyse cells. The cell lysate was centrifuged at $60,000 \mathrm{rpm}(100,000 \times \mathrm{g})$ at $4^{\circ} \mathrm{C}$ for 20 min in a Beckman ultracentrifuge to isolate cell membranes. The resultant membrane pellet was suspended in $75 \mu \mathrm{l}$ of $10 \%$ SDS containing $100 \mathrm{~mm}$ DTT, $80 \mathrm{ng} / \mathrm{ml}$ microcystin, $200 \mu \mathrm{M}$ phenylmethylsulfonyl fluoride, a 1:100 dilution of protease inhibitor mixture (see above), and $25 \mu \mathrm{l}$ of $4 \times$ sample 
buffer. Twenty-five microliters of this total $100 \mu$ l were typically loaded onto an SDS-PAGE gel.

Surface biotinylation. We followed the protocol of Ehlers (2000). Briefly, monolayers of COS cells were rinsed with progressively cooler washes of PBS plus $1 \mathrm{~mm} \mathrm{MgCl}_{2}$ and $2.5 \mathrm{mM} \mathrm{CaCl}_{2}$ (PBS $2+$ ), followed by a $20 \mathrm{~min}$ incubation with $1.5 \mathrm{mg} / \mathrm{ml}$ sulfo-NHS-SS-biotin (Pierce, Rockford, IL) in PBS $2+$ at $4^{\circ} \mathrm{C}$. Unreacted biotin was quenched by rinsing three times for 5 min with ice-cold $50 \mathrm{~mm}$ glycine in PBS $2+$. Membrane proteins were harvested as described above except with a $5 \%$ rather than a $10 \%$ SDS concentration. This membrane fraction was then incubated with a 1:1 slurry of BSA-blocked neutravidin beads (Pierce) for $2 \mathrm{hr}$ at room temperature. The beads were rinsed three times with HB (above) plus $1 \%$ Triton X-100 before proteins were eluted with $1 \times$ sample buffer.

Western blotting. Membrane proteins were loaded and run on a $7.5 \%$ acrylamide gel to resolve Kv4.2 and a 10\% acrylamide gel to resolve ERK-MAPK. Gels were then blotted electrophoretically to Immobilon filter paper using a transfer tank maintained at $4^{\circ} \mathrm{C}$, with typical parameters being an overnight transfer at a constant current of $250 \mathrm{~mA}$ (transfer buffer: $192 \mathrm{~mm}$ glycine, $25 \mathrm{~mm}$ Tris, $\mathrm{pH}$ 8.3). Immobilon filters were blocked for $1 \mathrm{hr}$ at room temperature in Blotto (10 mM Tris- $\mathrm{HCl}, \mathrm{pH} 7.5$, $150 \mathrm{~mm} \mathrm{NaCl}, 0.05 \%$ Tween $20,5 \%$ powdered milk, and $0.01 \%$ thimerosal). All antibody applications were done in Blotto. Primary antibody concentrations were as follows: 1:500 Kv4.2 polyclonal antibody from Chemicon (Temecula, CA), 1:2 Kv4.2 monoclonal antibody K57/41.1 from the Trimmer Laboratory (Shibata et al., 2003), and 1:3000 total ERK from Cell Signaling Technology (Beverly, MA).

Antibody detection. Immobilon filters were incubated sequentially with primary antibody and a biotin-labeled goat anti-rabbit IgG secondary antiserum $(1: 20,000)$ and then developed using enhanced chemiluminescence (Amersham Biosciences). Blots were washed extensively in $50 \mathrm{~mm}$ Tris- $\mathrm{HCl}, \mathrm{pH} 7.5,150 \mathrm{~mm} \mathrm{NaCl}$, and $0.05 \%$ Tween 20 after incubations with primary and secondary antibodies (typically, four washes of 10 min each).

Functional expression in Xenopus oocytes. Oocytes were harvested from the ovarian lobe of female Xenopus laevis frogs (Schrader et al., 2002). Briefly, the frog was anesthetized by submersion in $0.15 \%$ tricaine. The ovarian lobe was then surgically removed and placed in $\mathrm{Ca}^{2+}$-free OR2 solution (in mM: $82.5 \mathrm{NaCl}, 2.5 \mathrm{KCl}, 1 \mathrm{MgCl}_{2}$, and $5 \mathrm{HEPES}$ ). The frog was allowed to recover and placed back in the tank. The oocytes were digested in 1.6-2.4 mg/ml collagenase (Boehringer Mannheim) for several hours. Digested oocytes were then incubated in ND-96 (in mM: 96 $\mathrm{NaCl}, 2 \mathrm{KCl}, 1.8 \mathrm{CaCl}_{2}, 1 \mathrm{MgCl}_{2}$, and 5 HEPES, pH 7.4) supplemented with pyruvic acid ( $2.5 \mathrm{mM})$ and gentamicinsulfate $(50 \mathrm{mg} / \mathrm{ml}$; Invitrogen, San Diego, CA). After $\sim 24 \mathrm{hr}$, oocytes were injected with $16 \mathrm{ng}$ of each DNA construct using a Nanoject microinjector (Drummond Scientific Co.) into the nucleus of stage V-stage VI oocytes. Currents were recorded after 2-3 d under two-electrode voltage-clamp using an Axoclamp 2A amplifier (Axon Instruments) at room temperature. Microelectrodes were pulled from filamented glass $(1.5 \times 0.86 \mathrm{~mm}$; A-M Systems $)$ filled with $3 \mathrm{M} \mathrm{KCl}$. The current electrode had resistance of $0.3-0.5 \mathrm{M} \Omega$, whereas the voltage electrode ranged from 0.3 to $1 \mathrm{M} \Omega$. Currents were leak-subtracted on-line using $\mathrm{P} / 4$ leak subtraction. Data were digitized at $2 \mathrm{kHz}$ and stored using a Digidata 1200. Current protocols used to obtain data include activation (hyperpolarization to $-110 \mathrm{mV}$ and then depolarization to $+40 \mathrm{mV}$ for $400-800 \mathrm{msec}$, repeated in $-5 \mathrm{mV}$ step intervals) and inactivation (depolarization to $0 \mathrm{mV}$ and then hyperpolarization to $-110 \mathrm{mV}$ for $650 \mathrm{msec}$, changing this step by $+5 \mathrm{mV}$ intervals, then depolarization to $0 \mathrm{mV}$ ). The chamber was continuously perfused with ND-96 and with $\mathrm{NaOH}$ at a rate of 3-6 ml/min. Data were analyzed using Clampfit, Origin, and Prism programs. Peak currents were obtained, and conductance was determined using a reversal potential of $-95 \mathrm{mV}$. Activation and inactivation curves were fit with a Boltzman sigmoidal curve with the following equation: $Y=$ Bottom + (Top Bottom $) /\left[1+\exp \left(\left[V_{1 / 2}-X\right] /\right.\right.$ Slope $\left.)\right]$.

Hippocampal primary culture and transfection. Hippocampal cell cultures were prepared as described previously (Wu et al., 2001). Briefly, hippocampal CA1-CA3 regions were dissected from 0 - to 3-d-old Sprague Dawley rats, dissociated by trypsin treatment followed by trituration with a siliconized Pasteur pipette, and then plated onto coverslips coated with matrigel (1:50). Culture media consisted of minimal essential media (MEM; Invitrogen), $0.6 \%$ glucose, $0.1 \mathrm{gm} / 1$ bovine transferrin (Calbiochem, La Jolla, CA), $0.25 \mathrm{gm} / \mathrm{l}$ insulin (Sigma), $0.3 \mathrm{gm} / \mathrm{lglu}$ tamine, $5-10 \%$ fetal calf serum (FCS; Sigma), 2\% B-27 supplement (Invitrogen), and $2 \mu \mathrm{M}$ cytosine-D-arabinofuranoside (Sigma). Cultures were maintained at $37^{\circ} \mathrm{C}$ in a $95 \%$ air, $5 \% \mathrm{CO}_{2}$-humidified incubator.

The calcium phosphate transfection method (Xia et al., 1996) was used to transfect the neurons. Briefly, 3-7 d in vitro cell cultures were washed twice with fresh, serum-free medium (MEM plus $5 \mathrm{gm} / \mathrm{l}$ glucose) after saving original media. Thirty microliters of calcium phosphate precipitate-DNA mixtures were added to each coverslip, and cells were put back into the incubator for $30 \mathrm{~min}$. After washing twice with serum-free medium, the cells were returned to the incubator after adding back the original medium.

Electrophysiology. A Zeiss (Oberkochen, Germany) Axioskop, fitted with a $40 \times$ water-immersion objective and differential interference contrast, was used to view cultured cells and neurons. Transfected cells and neurons expressing enhanced GFP (EGFP) were identified under a fluorescent microscope. Whole-cell voltage clamp and outside-out patch clamp were done in Chinese hamster ovary (CHO)-K1, COS-7, and cultured hippocampal pyramidal neurons using an Axopatch 200 amplifier. All experiments were performed at RT. For CHO and COS, the bath solution contained (in mM): $134 \mathrm{NaCl}, 2 \mathrm{KCl}, 5.6 \mathrm{NaOH}, 1.8 \mathrm{CaCl}_{2}, 1$ $\mathrm{MgCl}_{2}$, and 10 HEPES, pH 7.4. The pipette solution contained (in $\mathrm{mm}$ ): $140 \mathrm{KCl}, 1 \mathrm{MgCl}_{2}, 1 \mathrm{EGTA}, 0.133 \mathrm{CaCl}_{2}$, a $\sim 10$ nM free $\mathrm{Ca}^{2+}$ concentration, and 10 HEPES, $\mathrm{pH}$ 7.4. The $\mathrm{K}^{+}$current reversal potential measured under this condition was approximately $-85 \mathrm{mV}$. The liquid junctional potential between pipette solution and bath solution was measured as -7 $\mathrm{mV}$ and was not corrected for all experiments.

For pyramidal neurons, the bath solution contained (in $\mathrm{mm}$ ): 125 $\mathrm{NaCl}, 2.5 \mathrm{KCl}, 25 \mathrm{NaHCO}_{3}, 2 \mathrm{CaCl}_{2}, 1 \mathrm{MgCl}_{2}$, and 10 dextrose. The pipette solution contained (in mM): $120 \mathrm{~K}$-gluconate, $20 \mathrm{KCl}, 10 \mathrm{HEPES}$, 0.2 EGTA, $2 \mathrm{Mg}_{2} \mathrm{Cl}, 4 \mathrm{Na}_{2} \mathrm{ATP}, 0.3$ Tris-GTP, and 14 phosphocreatine, $\mathrm{pH} 7.25$ (with $\mathrm{KOH}$ ). To isolate $\mathrm{K}^{+}$currents in pyramidal neurons, $1 \mu \mathrm{M}$ TTX and $2 \mathrm{mM} \mathrm{MnCl}_{2}$ were added to the bath to block $\mathrm{Na}^{+}$currents, $\mathrm{Ca}^{2+}$ currents, and $\mathrm{Ca}^{2+}$-activated $\mathrm{K}^{+}$currents. To isolate the transient component $\left(I_{\mathrm{A}}\right)$, a prepulse protocol (a voltage step to $-20 \mathrm{mV}$ for 100 msec before the test pulse) was used, and the difference between the currents elicited with and without the prepulse was measured. Pipettes had resistances of between 2 and $5 \mathrm{M} \Omega$. Whole-cell capacitance and series resistances were compensated to $>80 \%$, and in addition, series resistances were less than two times the tip resistance. Pulse generation and data acquisition were controlled with custom software written for the Igor Pro analysis environment. Leakage and capacitive currents were digitally subtracted on-line.

Whole-cell current-clamp recordings were made using an Axoclamp 2A (Axon Instruments) amplifier in "bridge" mode at room temperature and were analog-filtered at $3 \mathrm{kHz}$. Series resistances were in the range of 10-15 M $\Omega$. Heteropodatoxin-3 (HpTx-3) (NPS Pharmaceuticals, Salt Lake City, UT) was dissolved in water and added to the external solution with $0.1 \%$ BSA.

Data analysis. Data were analyzed by using a self-written analysis program in Igor. Steady-state activation and steady-state inactivation curves were constructed and fitted with the normalized Boltzmann equation. Time course of the recovery from inactivation was fitted with single exponentials. The current inactivation kinetic was also determined by single exponential fitting.

Significance $(p<0.05)$ among multiple groups was determined by ANOVA. A paired or two-sample $t$ test was used when comparisons were restricted to two means. Error bars represent SEM.

\section{Results}

\section{CaMKII phosphorylates the $\mathrm{C}$ terminus of Kv4.2 in vitro}

To determine whether Kv4.2 is phosphorylated by CaMKII, we expressed the cytoplasmic $\mathrm{N}$ and $\mathrm{C}$ termini of Kv4.2 as GST fusion proteins, purified them using affinity chromatography, and exposed these proteins to ${ }^{32} \mathrm{P}$-labeled ATP, CaMKII, and the appropriate cofactors in vitro. The proteins were separated via SDS- 
PAGE, and autoradiography revealed ${ }^{32} \mathrm{P}$ labeling in the $\mathrm{C}$ terminus but not in the $\mathrm{N}$ terminus of Kv4.2 (Fig. 1A). GST alone was not phosphorylated by CaMKII (data not shown). To determine the phosphorylation sites within the $\mathrm{C}$ terminus, we first separated CaMKII-phosphorylated C-terminal fusion protein via SDS-PAGE and stained bands with Coomassie blue. The band representing the $\mathrm{C}$ terminus was excised, eluted, and digested with Lys-C. We then performed phosphopeptide mapping and amino acid sequencing of the phosphorylated Kv4.2 C-terminal fusion protein to directly determine sites of CaMKII phosphorylation.

Two CaMKII phosphorylation sites were identified in the C-terminal cytoplasmic domain. The phosphopeptide map for the C-terminal construct demonstrated three peaks in radioactivity in HPLC fractions (Fig. 1C) corresponding to four HPLC absorbance peaks (Fig. $1 B$ ). These HPLC fractions were directly sequenced using automated Edman degradation, and the amount of radioactivity released with each sequencing cycle was measured (Fig. 1D,E). This revealed two phosphopeptides: one corresponding to Kv4.2 C-terminal residues 438-444, with a phosphorylation site at Ser438 (Fig. 1D), and another corresponding to $\mathrm{Kv} 4.2$ C-terminal residues 449-468, with a phosphorylation site at Ser459 (Fig. 1E). The Kv4.2 sequence from amino acids $432-445$ is RIRAAKSGSANAYM, and the sequence from amino acids $453-466$ is LSNQLQSSEDEPAFV. Thus the Ser438 phosphorylation site is more of a prototypical CaMKII phosphorylation site, containing an immediately preceding lysine and several other preceding positive charges. These data thus implicate CaMKII in Kv4 channel regulation.

\section{CaMKII phosphorylation of Kv4.2 leads to increased total cellular Kv4.2 protein}

Because the above data supported the hypothesis that CaMKII regulates Kv4.2 through direct phosphorylation, we subsequently wanted to determine the functional effect of such phosphorylation. To do so, we used two approaches. One approach entailed coexpression of Kv4.2 with either of two truncated, constitutively active forms of CaMKII to test for effects of CaMKII on Kv4.2. One version of CaMKII was truncated at amino acid 316 (hereafter referred to as CaMKII $\Delta 316$ ) (Lledo et al., 1995), and the other is a GFP-labeled, truncated version of CaMKII (hereafter referred to as tCaMKII) (Hayashi et al., 2000). The second approach was to use site-directed mutagenesis to test the specificity of the two CaMKII phosphorylation sites we identified.

We transfected wild-type Kv4.2 plus an accessory subunit KChIP3 and tCaMKII or GFP into COS-7 cells and harvested these cells $24 \mathrm{hr}$ after transfection. KChIP3 was included because it promotes channel synthesis and renders the channel properties
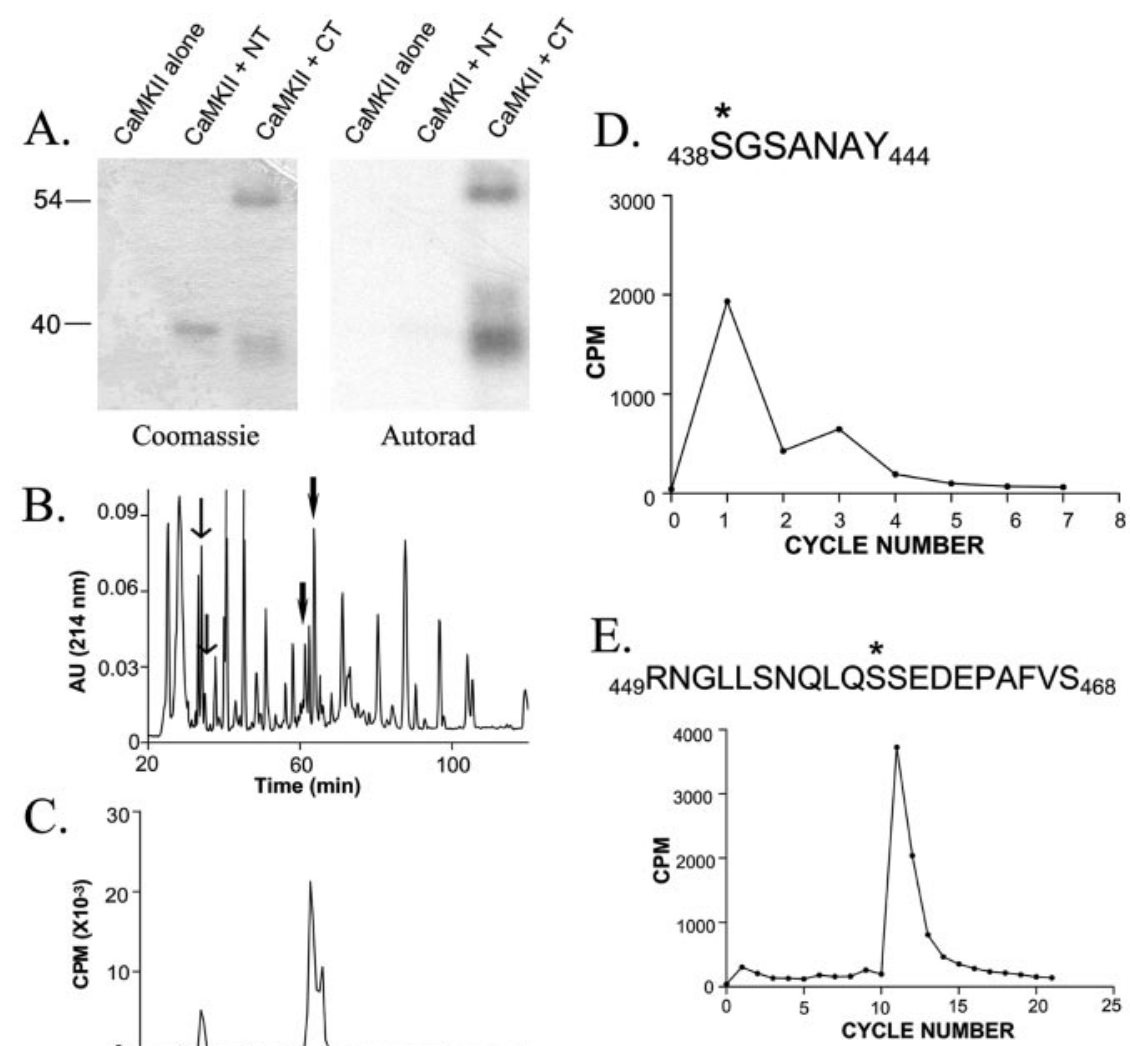

Figure 1. In vitro phosphorylation of Kv4.2 and identification of CaMKIl-phosphorylated residues. A, Purified recombinant GST proteins expressing the N-terminal (NT) or C-terminal (CT) cytoplasmic domains of Kv4.2 were reacted with CaMKII and the appropriate cofactors in vitro. Proteins were separated via SDS-PAGE. Left, Coomassie staining of proteins. Right, Autoradiogram demonstrating ${ }^{32} \mathrm{P}$ incorporation into the C terminus only. B, Phosphopeptide mapping was performed after CaMKII phosphoryThere is a peak in sequence cycle 12 for the peptide containing amino acids $449-465$, indicating that Ser 459 is the phosphorylated amino acid in that peptide $(E)$. Phosphorylated residues are marked with an asterisk.

more native-like (An et al., 2000; Schrader et al., 2002). We then prepared membrane fractions from these cells, separated proteins via SDS-PAGE, and probed for total Kv4.2 protein via Western blotting. When Kv4.2 was cotransfected with tCaMKII, there appeared to be an approximately fourfold increase in total Kv4.2 protein immunoreactivity $(374 \pm 70 \%$ of control; $n=13 ; p<$ 0.05 ) (Fig. $2 A-C$ ). To verify that the changes in immunoreactivity seen with constitutive CaMKII expression were not an artifact of increased availability of the particular epitope recognized by the Kv4.2 antibody we used (Chemicon), we demonstrated that the immunoreactivity to $\mathrm{Kv} 4.2$ in the membrane fraction also increased when a monoclonal antibody recognizing an extracellular epitope of Kv4.2 was applied (Fig. 2D). These data demonstrate an effect of CaMKII on Kv4.2, specifically a pronounced increase in protein expression levels.

To ascertain, in part, whether this effect was mediated by the Kv4.2 phosphorylation sites we had identified, we used sitedirected mutagenesis to convert Ser438 and Ser459 to alanines to prevent phosphorylation and also converted the sites to aspartates to mimic constitutive phosphorylation. When the S438D- 
A.

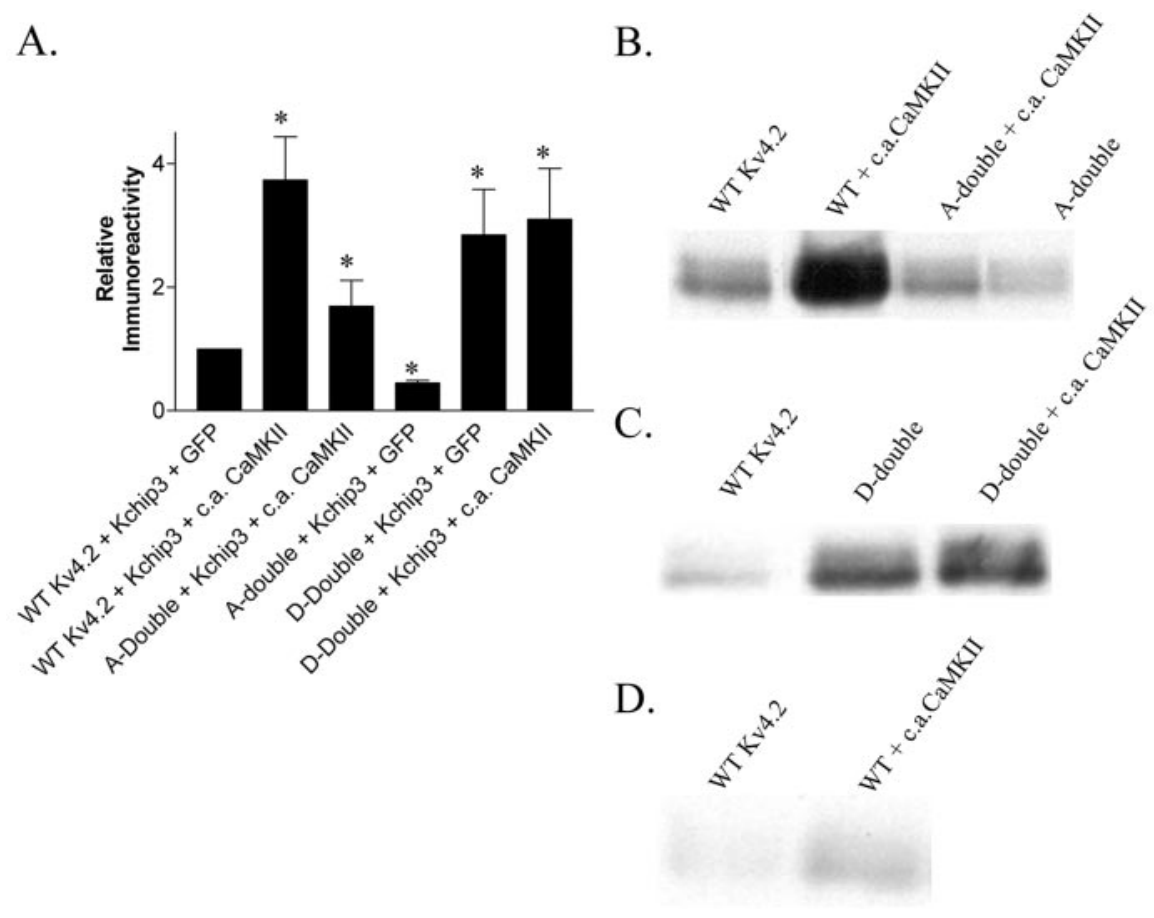

B.

Figure 2. Changes in immunoreactivity against Kv4.2 by coexpression of constitutively active CaMKII or mutating the identified CaMKII phosphorylation sites. $A$, Expression of either the tCaMKII or the $\Delta 316$ constitutively active form of CaMKII (collectively labeled c.a. (aMKII) instead of GFP, along with Kv4.2 and KChIP3, increased the immunoreactivity against Kv4.2 in the membrane proteins harvested from transfected $\operatorname{COS}$ cells ( $374 \pm 70 \%$ of control; $n=13 ; p<0.05)$. CaMKII failed to have as large an effect on Kv4.2 where both Ser438 and Ser 459 have been mutated to alanines (A-double) (169 $\pm 84 \%$ of control; $n=4 ; p<0.05$ ). The A-double-mutant in the absence of constitutively active CaMKII was decreased compared with control ( $45 \pm 4 \%$ of control; $n=$ $4 ; p<0.05$ ). Mutagenesis of both Ser438 and Ser459 to aspartates to mimic constitutive phosphorylation (D-double) recapitulated the CaMKII effect ( $287 \pm 74 \%$ of control; $n=16 ; p<0.05$ ). Addition of constitutively active CaMKII to the D-double-mutant failed to add substantially to the effect of the D-double-mutant in the absence of constitutively active CaMKII ( $309 \pm 82 \%$ of control; $\left.n=9 ;{ }^{*} p<0.05\right) . B$, Representative Western blot showing the effect of CaMKIll activity on Kv4.2 immunoreactivity as well as the effect of mutating the two CaMKII phosphorylation sites to alanines. C, A separate representative Western blot showing the effect of introducing aspartates into the two identified CaMKII phosphorylation sites. D, CaMKII phosphorylation does not simply change the availability of the antibody epitope, because the same phenomenon is observed with a separate monoclonal Kv4.2 antibody. WT, Wild type.

S459D double-mutant was transfected into COS cells with KChIP3, the total level of Kv4.2 immunoreactivity mimicked the increased immunoreactivity on Western blots seen with the cotransfection of tCaMKII $(287 \pm 74 \%$ of control; $n=16 ; p<0.05)$ (Fig. $2 A, C$ ). This phenotype was unchanged after cotransfection with tCaMKII (309 $\pm 82 \%$ of control; $n=9$; $p<0.05)$. Conversely, when the double-mutant S438A-S459A was introduced into COS cells, there was a significant reduction in immunoreactivity for Kv4.2 (45 $\pm 4 \%$ of control; $n=4 ; p<0.05$ ) (Fig. $2 A, B$ ). When tCaMKII was cotransfected with the double-mutant S438A-S459A, the total immunoreactivity of Kv4.2 increased, but not nearly to the extent that the wild-type channel was modified ( $169 \pm 84 \%$ of control; $n=4 ; p<0.05$ ). This suggests that there may be multiple mechanisms by which CaMKII affects $\mathrm{Kv} 4.2$; however, the primary mechanism appears to be via direct phosphorylation of the $\mathrm{C}$ terminus of Kv4.2 at the identified phosphorylation sites. Overall, these results suggested to us that CaMKII may be regulating either the net rate of creation or degradation of the Kv4.2 channel; however, we favor the idea of degradation, because the effects of the apartate point mutants must of necessity be post-translational.

Because the immunoreactivity of the S438A-S459A doublemutant was low and sometimes not even detectable, we decided to ensure that we could accumulate this mutant channel by in- hibiting its degradation. Therefore, we applied the proteasome inhibitor MG132 at $20 \mu \mathrm{M}$ for $12 \mathrm{hr}$. We found that inhibiting the proteasome in such a manner led to recovery of protein in the S438A-S459A Kv4.2 mutant and increased overall channel protein immunoreactivity in all variants of Kv4.2 (Fig. 3A). These observations suggest that $\mathrm{Kv} 4.2$ is at least in part degraded by the proteasome and that CaMKII may somehow be regulating the net half-life of the protein in the cell. This might occur by trafficking the channel to a stabilized pool or decreasing the rate of protein breakdown.

It has become increasingly clear that ubiquitination of proteins is an important regulatory step in protein degradation and cycling proteins into and out of cell membranes, particularly for proteins associated with the postsynaptic density (Ehlers, 2003). Because we had already shown that Kv4.2 was capable of being regulated by the proteasome and that CaMKII phosphorylation causes cellular accumulation of Kv4.2, we took particular notice of a lysine residue at amino acid 437, immediately preceding one of the CaMKII phosphorylation sites at Ser438. We hypothesized that phosphorylation of Ser438 might be blocking access of a ubiquitin ligase to Lys437, thereby leading to a stalling of the degradation process. To test this hypothesis, we used site-directed mutagenesis to introduce an alanine at the Lys437 position of Kv4.2. We suspected that the total Kv4.2-like immunoreactivity of the K437A mutant of Kv4.2 might be increased in the same way the S438D-S459D mutant total immunoreactivity is increased in COS cells. However, the K437A mutant displayed significantly decreased total immunoreactivity compared with wild-type channel (Fig. 3B). This result suggests that Lys437 is not involved in Kv4.2 degradation, and we interpret the decrease in immunoreactivity to represent an inability of CaMKII to properly recognize the mutant $\mathrm{Kv} 4.2$, thereby resulting in decreased phosphorylation of the channel. This model is consistent with the known role of upstream positively charged residues as being involved in the CaMKII substrate recognition consensus sequence.

In our Western blotting experiments, we made the serendipitous observation that Kv4.2 is often processed into a doublet of immunoreactivity (Fig. $4 B$ ). Thus, we were intrigued by the observation that inhibiting CaMKII activity pharmacologically with $10 \mu \mathrm{M} \mathrm{KN}-93$ could alter the immunoreactivity of Kv4.2 from a doublet to a singlet in transfected COS cells (Fig. 4A) along with decreasing total Kv4.2 protein as expected. The effect on the CaMKII doublet was first observed when KN-93 was present in the media $18 \mathrm{hr}$ before harvesting the cells. Previous observations have suggested that the upper band of immunoreactivity represents protein specifically trafficked to the cell surface, whereas the lower band represents a pool of channel that can exist either intracellularly or at the surface (Shibata et al., 2003). We confirmed these previous observations by applying the Golgi traffick- 


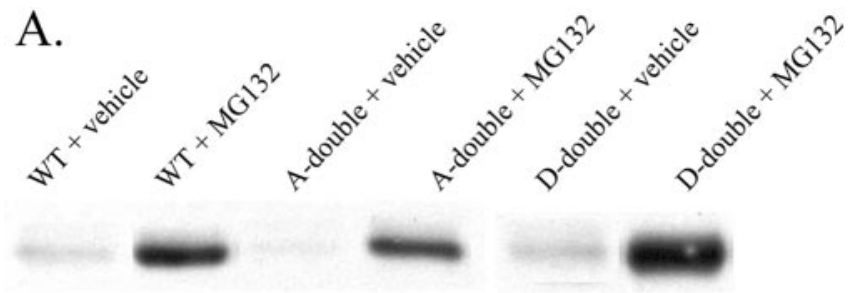

B.

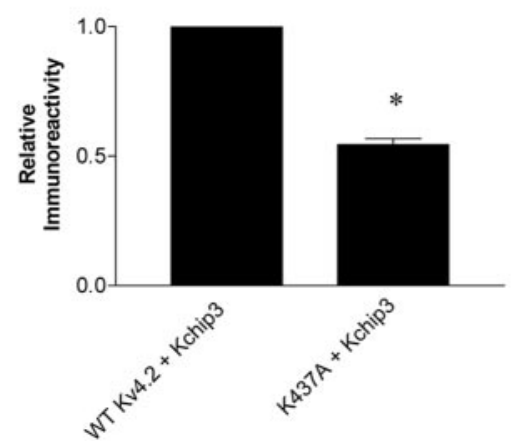

Figure 3. Inhibition of the proteasome causes accumulation of Kv4.2. A, To ascertain the presence of a band in the S4348A-S459A double-mutant of Kv4.2, we applied a $21 \mu \mathrm{m}$ concentration of the proteasome inhibitor MG132 to transfected COS cells for $12 \mathrm{hr}$. Obvious accumulation of protein in the wild-type (WT) channel, the S438A-S459A double-mutant (A-double), and the S438D-S459D double-mutant (D-double) was seen with MG132 after harvesting the cells. B, To test the hypothesis that Lys437, immediately preceding CaMKII phosphorylation site Ser438, is involved in the ubiquitin-mediated degradation of Kv4.2, we substituted Lys 437 for an alanine. This mutant of Kv4.2 displayed decreased immunoreactivity when cotransfected with KChIP3 in COS cells compared with the wild-type channel plus KChIP3 ( $54 \pm 4 \%$ of control; $\left.n=3 ;{ }^{*} p<0.05\right)$. Our interpretation of this result is that Lys 437 does not play a role in ubiquitin-mediated degradation of Kv4.2 but may be necessary as part of the consensus sequence for CaMKII recognition of Ser438.

ing inhibitor Brefeldin A to COS cells transfected with wild-type Kv4.2 and KChIP3 with or without tCaMKII at the time of transfection. The immunoreactivity of Kv4.2 from cells expressing either channel alone or channel plus tCaMKII was consistently restricted to the lower molecular weight band after Brefeldin A treatment (Fig. $4 B$ ), suggesting to us the hypothesis that CaMKII may be specifically increasing the surface pool of Kv4.2 concurrently with increasing total cellular protein.

We therefore tested the hypothesis that CaMKII phosphorylation might regulate the extent of cell-surface expression of Kv4.2 through several independent means. First, we biotinylated the surface proteins of COS cells expressing Kv4.2 and KChIP3 and either tCaMKII or GFP and then pulled down these biotinylated proteins with neutravidin beads. Cells expressing tCaMKII displayed increased Kv4.2 in this surface pool compared with those cells expressing GFP plus Kv4.2 (Fig. 4C). Analysis of the nonsurface pool of $\mathrm{Kv} 4.2$ also showed an increase in immunoreactivity (data not shown), and this finding is consistent with the hypothesis that CaMKII activity increases both the cell-surface pool and the total cellular content of Kv4.2. In an additional test to determine whether CaMKII increases surface Kv4.2 expression, we took advantage of a C-terminal-directed, PKAphosphorylated Kv4.2 antibody that selectively recognizes Kv4.2 expressed at the cell surface (Anderson et al., 2000; Shibata et al., 2003). Importantly, this phosphoselective antibody does not nonspecifically cross-react with CaMKII-phosphorylated isoforms of Kv4.2 (Anderson et al., 2000). In brief, the antibody is a phospho-site-specific antibody that recognizes Kv4.2 when it is phosphorylated by PKA in its C-terminal domain (Anderson et al., 2000). Shibata et al. (2003), using this antiserum, found that it
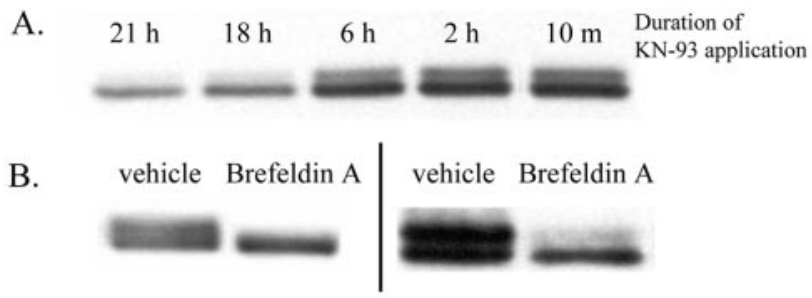

WT Kv4.2+

Kchip3 +

GFP
WT Kv4.2+

Kchip3 +

tCaMKII

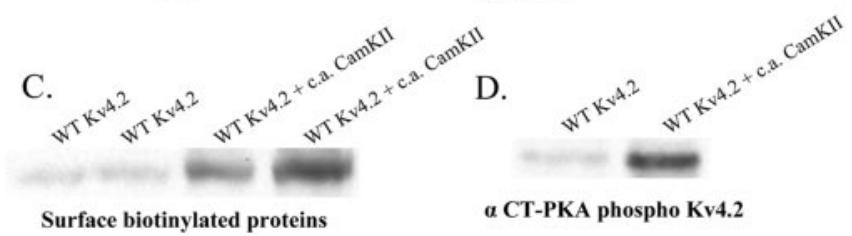

Figure 4. Treatment with KN-93 or Brefeldin A can change the immunoreactivity pattern of Kv4.2 from a doublet to a singlet. $A$, Immunoreactivity to Kv4.2 on a Western blot typically appears as a doublet, and CaMKII seemed to have a specific effect on increasing the immunoreactivity of the upper molecular weight species. We applied the CaMKII inhibitor KN-93 at 10 $\mu \mathrm{m}$ for various periods of time to $\mathrm{COS}$ cells expressing wild-type (WT) Kv4.2 and KChIP3. There is an obvious decrease in the immunoreactivity of the upper band of Kv4.2, beginning at $18 \mathrm{hr}$ of $\mathrm{KN}-93$ application. B, There has been previous evidence that this upper molecular weight band represents a pool of Kv4.2 trafficked to the surface and that the lower molecular weight band represents an intracellular pool of Kv4.2. To test this more directly, we applied the Golgi trafficking inhibitor Brefeldin A at $10 \mu \mathrm{g} / \mu \mathrm{l}$ for $12 \mathrm{hr}$ to COS cells expressing Kv4.2, KChIP3, and GFP; Kv4.2, KChIP3, and tCaMKIl; or the S438D-S459D double-mutant of Kv4.2, KChIP3, and GFP. We found that such treatment with Brefeldin A changed the immunoreactivity of Kv4.2 from a doublet to a single, lower molecular weight species. This supports the idea that the upper molecular weight band of Kv4.2 represents a pool of channel trafficked to the surface. C, Isolation of the surface pool of Kv4.2 in COS cells transfected with Kv4.2, KChIP3, and either tCaMKII or GFP by biotinylation and avidin pulldown reveals that CaMKII phosphorylation can increase the amount of Kv4.2 at the cell surface. Biotinylation of Kv4.2 causes a change in the electrophoretic mobility of the protein such that it runs at $200 \mathrm{kDa}$. D, CaMKII phosphorylation increases the immunoreactivity of a PKA-phosphorylated, phosphospecific antibody that has been shown previously to selectively label the cell surface.

selectively recognizes Kv4.2 when it is at the cell surface. The total immunoreactivity detected with this antibody is greater in COS cells expressing Kv4.2, KChIP3, and tCaMKII compared with those expressing Kv4.2, KChIP3, and GFP as a control (Fig. 4D). This result is consistent with the hypothesis that the Kv4.2 protein increase that we see is in part attributable to a change in cell-surface Kv4.2. In addition, the results with this antibody indicate that the increase in Kv4.2 immunoreactivity is not simply an idiosyncratic effect restricted to the immunoreactivity of a single antiserum. Together, the simplest explanation of our surface biotinylation experiments, surface-selective antibody Western blots, and Brefeldin A experiments is that CaMKII phosphorylation of $\mathrm{Kv} 4.2$ is causing an increase in the surface expression of Kv4.2. In our next series of studies, we added a physiological correlate to this biochemical evidence by recording surface membrane currents of Kv4.2 expressed in a heterologous cell expression system.

\section{Constitutively active CaMKII potentiates Kv4.2 currents in transfected COS cells}

To address the question of increased surface expression, we decided to measure whole-cell current density in expression systems. We transfected CaMKII $\Delta 316$ along with wild-type Kv4.2, KChIP3, and GFP into cultured COS cells. Twenty-four to $48 \mathrm{hr}$ after transfection, we performed whole-cell patch recordings on transfected COS cells identified by the GFP marker. The kinetics of expressed $I_{\mathrm{A}}$ shared much similarity with what was reported 
Table 1. Current kinetics of various expressed Kv4.2-encoded channels

\begin{tabular}{lll}
\hline & $\begin{array}{l}\text { Activation time } \\
\text { constant (msec) }\end{array}$ & $\begin{array}{l}\text { Inactivation time } \\
\text { constant (msec) }\end{array}$ \\
\hline Wild type $(n=10)$ & $3.2 \pm 0.3$ & $58.2 \pm 3.1$ \\
Wild type plus CaMKII $\Delta 316(n=7)$ & $3.8 \pm 0.4$ & $61.3 \pm 5.5$ \\
S438D-S459D $(n=8)$ & $4.0 \pm 0.7$ & $60.8 \pm 4.5$ \\
Wild type $(n=\sim 8-11)$ & $3.0 \pm 0.2$ & $53.2 \pm 2.6$ \\
S438A-S459A $(n=6)$ & $3.4 \pm 0.3$ & $58.2 \pm 5.1$ \\
S438A-S459A plus CaMKII $\Delta 316(n=9)$ & $3.1 \pm 0.2$ & $52.0 \pm 3.4$ \\
\hline
\end{tabular}

Above measurements were from currents elicited by a voltage step to $0 \mathrm{mV}\left(V_{\mathrm{h}}=-80 \mathrm{mV}\right)$. Multigroup comparisons within two groups showed no significant difference (ANOVA; $p>0.05$ ).

previously for Kv4.2 plus KChIP3 (An et al., 2000; Holmqvist et al., 2002), and we did not find a dramatic difference in the activation or inactivation time constant among various experimental groups (Table 1).

However, the average current density evoked from a step to $+20 \mathrm{mV}$ from a $-80 \mathrm{mV}$ holding potential was $191.8 \pm 23.8$ $\mathrm{pA} / \mathrm{pF}(n=13)$ for the wild-type channel and $422.9 \pm 52.4 \mathrm{pA} / \mathrm{pF}$ $(n=10)$ for those cells in which CaMKII $\Delta 316$ was cotransfected, representing a $>200 \%$ increase (Fig. 5A). Again, we were interested in confirming that this effect was being mediated in part by direct phosphorylation at the identified sites on the $\mathrm{C}$ terminus of $\mathrm{Kv} 4.2$, and we therefore used the phospho-site mutants in this assay system. The average current density in COS cells expressing the S438D-S459D double-mutant, when stepped to $+20 \mathrm{mV}$, was $526.7 \pm 70.3 \mathrm{pA} / \mathrm{pF}(n=10)$, thus recapitulating the effect of constitutively active CaMKII on native Kv4.2 currents. Conversely, the average current density mediated by the S438AS459A double-mutant in CHO cells was $180.8 \pm 47 \mathrm{pA} / \mathrm{pF}(n=$ 8 ) when stepped to $+20 \mathrm{mV}$, representing a substantial decrease compared with the wild-type channel expressed in $\mathrm{CHO}$ cells (wild-type current density at $+20 \mathrm{mV}, 371.1 \pm 26.4 \mathrm{pA} / \mathrm{pF} ; n=$ 12). CaMKII activity, however, could not potentiate the current density mediated by this double A-mutant channel, resulting in a similar current density $(217.1 \pm 23.1 \mathrm{pA} / \mathrm{pF} ; n=9)$. These results indicate a necessity of phosphorylation at these sites for CaMKII to increase surface expression of Kv4.2 (Fig. 5B). Because we did not measure single-channel conductance of $\mathrm{Kv} 4.2$ or the mean open time, we cannot rule out a CaMKII effect on these parameters; however, the most parsimonious explanation for our findings is that CaMKII phosphorylation of Kv4.2 increases not only total cellular amounts of Kv4.2 but also a functionally relevant pool of Kv4.2 protein at the cell-surface plasma membrane, contributing to greater average whole-cell currents. This increase, however, was not attributable to changes in the voltage dependence of Kv4.2-mediated A-type channels, as shown below.

\section{Kv4.2 channel biophysics are unchanged by CaMKII phosphorylation}

Because phosphorylation events are often multifunctional, we wondered whether CaMKII phosphorylation altered the channel biophysical properties of Kv4.2 in addition to increasing the average peak current amplitude. To assess this, we examined the voltage-dependent properties of $\mathrm{Kv} 4.2$ subunits under various conditions in COS cells, CHO cells, and Xenopus oocytes. We found that the voltage dependence of activation and the voltage dependence of inactivation were unchanged by introduction of either alanine or aspartate into the 438 and 459 sites or by coexpression with constitutively active CaMKII (Fig. 6). All data are summarized in Table 2. These data suggest that CaMKII does not regulate the voltage dependence of activation or inactivation of Kv4.2. These data also serve as an important control, demonstrat-
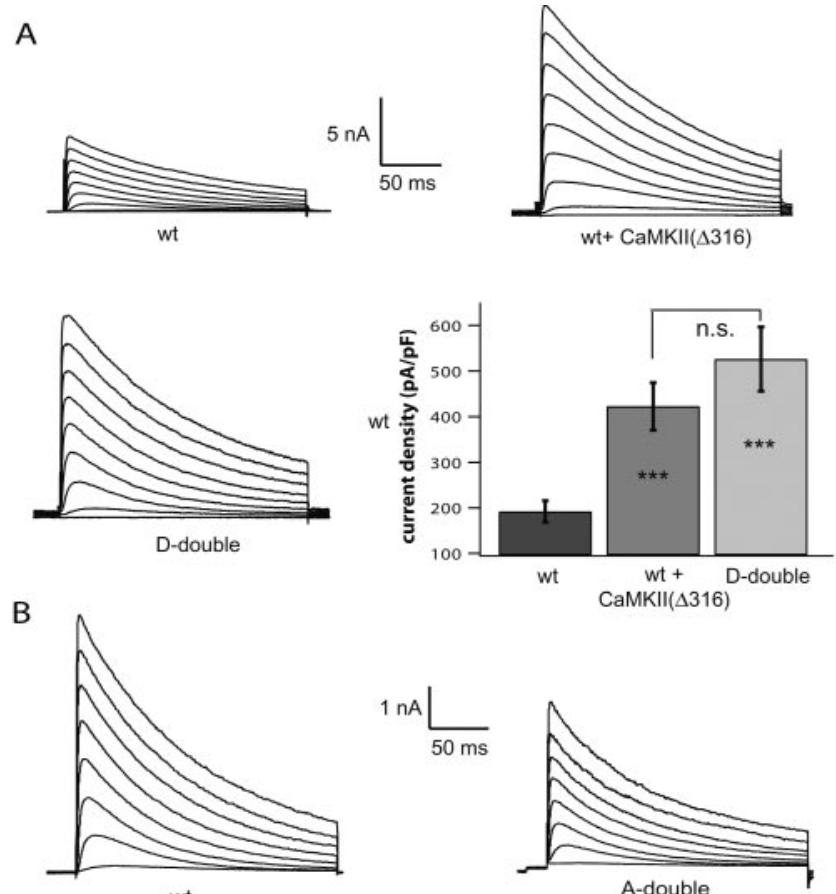

wt
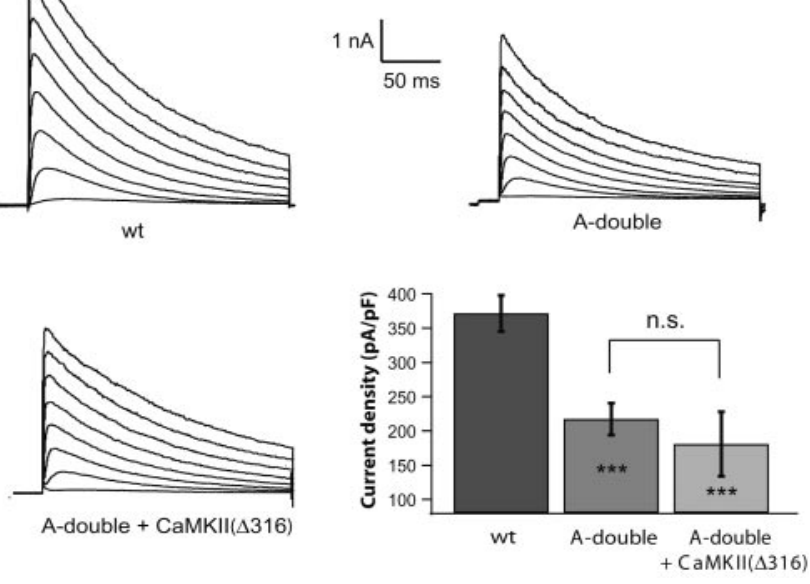

Figure 5. CaMKII activity can increase the peak current amplitude of Kv4.2 currents expressed in a heterologous system. $A$, We recorded the whole-cell current responses to a family of voltage steps in COS cells expressing wild-type (wt) Kv4.2, KChIP3, and either GFP (wild type) or constitutively active CaMKII ( $\Delta 316)$. The peak current amplitude of cells expressing constitutively active CaMKII was significantly greater than control $(191.8 \pm 23.8 \mathrm{pA} / \mathrm{pF}, n=13$, for the wild-type channel; $422.9 \pm 52.4 \mathrm{pA} / \mathrm{pF}, n=10$, for a voltage step to $+20 \mathrm{mV}$ from a $-80 \mathrm{mV}$ holding potential) for cells cotransfected with constitutively active CaMKII. Similarly, the S438D-S459D double-mutant (D-double) plus KChIP3 and GFP displayed significantly increased peak current amplitudes compared with the wild-type channel $(526.7 \pm 70.3 \mathrm{pA} / \mathrm{pF}$, $n=10$, for the same voltage step). ${ }^{* *} p<0.005$; ANOVA. Asterisks within bars indicate a significant change compared with control. n.s., Not significant. B, Expression of the S438AS459A double-mutant (A-double) plus KChIP3 and GFP in CHO cells resulted in significantly decreased peak current amplitudes in response to a family of voltage steps compared with the wild-type channel plus KChIP3 and GFP (wt) $(371.1 \pm 26.4 \mathrm{pA} / \mathrm{pF}, n=12$, for wt; $180.8 \pm 47$ $\mathrm{pA} / \mathrm{pF}, n=8$, for $5438 \mathrm{~A}-\mathrm{S} 549 \mathrm{~A})$. This reduction in peak current amplitude could not be rescued by addition of constitutively active CaMKII, demonstrating the specificity of the sites (217.1 \pm 23.1 pA/pF; $n=9$ for S438A-S459A plus KChIP3 and constitutively active (aMKII). ${ }^{* * *} p<$ 0.005; ANOVA. Asterisks within bars indicate a significant change compared with control. n.s., Not significant.

ing that the mutant channels are functionally, and thus most likely structurally, indistinguishable from native Kv4.2 in their basic properties. In other words, the decrease in Kv4.2 current expression with the serine-to-alanine mutants is not attributable to rendering the channel incapable of conducting potassium ions or detecting changes in membrane potential.

\section{CaMKII potentiates A-type currents in hippocampal pyramidal neurons}

There is evidence to suggest that $\mathrm{Kv} 4.2$ underlies the A-type $\mathrm{K}^{+}$ current in the somata and dendrites of hippocampal pyramidal 


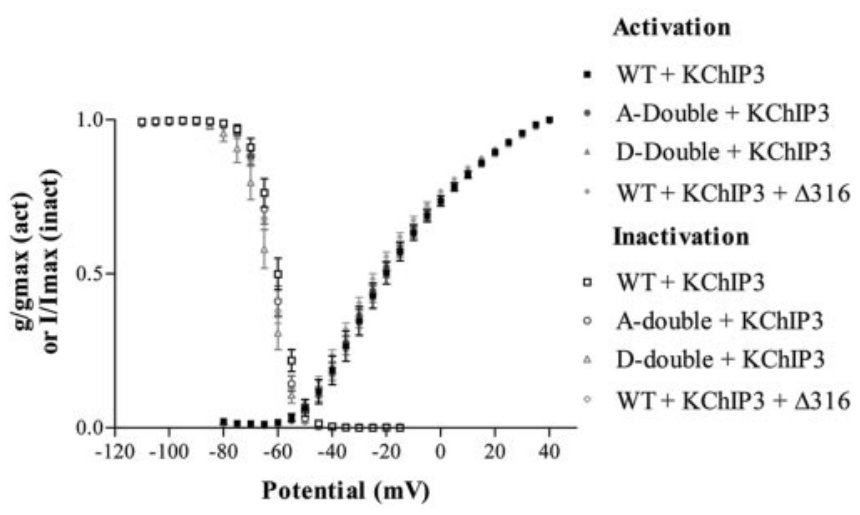

Figure 6. CaMKII does not affect the biophysical properties of the Kv4.2 channel. To assess whether CaMKII could affect the biophysical properties of the Kv4.2 channel, we expressed Kv4.2, KChIP3, and GFP in Xenopus oocytes and used a two-electrode voltage clamp to perform activation and inactivation protocols. Neither constitutively active CaMKII ( $\Delta 316)$ expression nor substitution of the CaMKII phosphorylation sites with alanines (A-double-mutant) or aspartates (D-double-mutant) affected the voltage dependence of activation or inactivation. WT, Wild type.

neurons (Serodio and Rudy, 1998; Song et al., 1998; Tkatch et al., 2000). Because we observed a CaMKII-mediated increase in Kv4.2 currents expressed in a heterologous expression system, we decided to test whether CaMKII could also regulate native A-type current in neurons. To this end, we transfected tCaMKII and GFP into dissociated cultured hippocampal neurons. We used CA1CA3-enriched primary cultures, including CA1 pyramidal neurons, CA3 pyramidal neurons, and various types of interneurons. To avoid variations in native $I_{\mathrm{A}}$ density and to reduce the complexity of the molecular identity of native $I_{\mathrm{A}}$ among different cell types, we chose to restrict our studies to responses from presumed CA1 pyramidal neurons. Our criteria for a CA1 pyramidal neuron included the presence of a major apical dendrite, some basal dendrites, and a relatively small soma that had whole-cell capacitance of $<20 \mathrm{pF}$ (Fig. $7 A$ ). Twenty-four to $48 \mathrm{hr}$ after transfection, we recorded whole-cell $\mathrm{K}^{+}$currents from expressing neurons, and the transient A-current component was isolated by a prepulse voltage protocol (Fig. $7 B$ ). Most recordings were obtained from GFP control and tCaMKII-GFP fusion constructexpressing neurons with similar shapes and sizes. In addition to Kv4 subunits, Kv1.4 subunits were also expressed in hippocampal pyramidal neurons (Veh et al., 1995; Grosse et al., 2000); thus they may also underlie the native $I_{\mathrm{A}}$ of CA1 pyramidal neurons. It was reported that CaMKII activity also regulates Kv1.4-mediated currents in an expression system (Roeper et al., 1997). One of the aspects of regulation was that the channel inactivation was dramatically slowed by CaMKII activity, resulting in a larger time constant $(\tau)$ of current decay. Under our experimental condition, when GFP neurons were held at $-80 \mathrm{mV}$ and stepped to $0 \mathrm{mV}$, the averaged $\tau$ was $24.5 \pm 1.7 \mathrm{msec}$. To avoid the contribution from Kv1.4 subunits in the native $I_{\mathrm{A}}$ amplitude upregulated by CaMKII, we focused our studies on these tCaMKII-expressing neurons with a current decay $\tau$ that was not larger than $35 \mathrm{msec}$. The mean $\tau$ of these tCaMKII neurons was $29.2 \pm 2.2 \mathrm{msec}$ and is not statistically different from that of GFP control ( $p>0.1)$. The peak A-current amplitude obtained from a step to $0 \mathrm{mV}$ from a holding potential of $-80 \mathrm{mV}$ in tCaMKII-expressing neurons was significantly greater than the current density obtained in control neurons $(624.1 \pm 79.2 \mathrm{pA}, n=11$ for control neurons vs $1162.3 \pm 67.2 \mathrm{pA}, n=14$ in tCaMKII expressing neurons) (Fig. $7 C)$. Although it was observed that the somata of tCaMKII neurons tended to be somewhat round in shape compared with that of GFP control, the difference in whole-cell capacitance (an indicator of cell size) was not statistically significant $(p>0.5)$ between tCaMKII neurons and GFP control. As a result, the current density of tCaMKII neurons $(78.8 \pm 4.9 \mathrm{pA} / \mathrm{pF})$ was significantly larger than control $(38.7 \pm 3 \mathrm{pA} / \mathrm{pF} ; p<0.001)$ (Fig. $7 D)$. These results demonstrate that CaMKII has the ability to upregulate the amplitude of somatodendritic A-type currents in hippocampal neurons. Thus, the effect of CaMKII on Kv4.2-encoded A-currents is likely not limited to heterologous systems, but also occurs in native neurons expressing endogenous A-type channels.

\section{Constitutive CaMKII expression alters hippocampal neuronal firing properties}

Because the A-type $\mathrm{K}^{+}$current $\left(I_{\mathrm{A}}\right)$ is important for regulating neuronal excitability and the repetitive firing of neurons, we hypothesized that the CaMKII-mediated increase in neuronal A-currents might affect the firing properties of hippocampal pyramidal neurons. We compared the responses of control hippocampal pyramidal neurons and neurons that had been transfected with constitutively active CaMKII. As described above, recordings were obtained from GFP- and tCaMKII-expressing neurons with similar shapes and sizes. First, the resting membrane potential $\left(V_{\mathrm{m}}\right)$ of tCaMKII neurons was more depolarized than that of GFP control cells $(59.7 \pm 1.5 \mathrm{vs}-68.3 \pm 3.1 \mathrm{mV} ; n=$ $7 ; p<0.05$ ) (Fig. 8C). Second, tCaMKII caused a small but statistically significant increase in threshold current $(21.7 \pm 3 \mathrm{pA}$; $n=7)$ compared with GFP-expressing neurons (13.5 $\pm 1.3 \mathrm{pA}$;

Table 2. Voltage-dependent properties of various Kv4.2-encoded $\mathrm{K}^{+}$currents

\begin{tabular}{|c|c|c|c|c|}
\hline & \multicolumn{2}{|l|}{ Activation } & \multicolumn{2}{|l|}{ Inactivation } \\
\hline & $V_{1 / 2}(\mathrm{mV})$ & Rate & $V_{1 / 2}(\mathrm{mV})$ & Rate \\
\hline \multicolumn{5}{|l|}{$\cos$} \\
\hline Wild type $(n=5)$ & $-6.1 \pm 3.5$ & $22.5 \pm 0.8$ & $-70.3 \pm 2.3$ & $8.2 \pm 1.1$ \\
\hline Wild type plus CaMKII $\Delta 316(n=4)$ & $-13.7 \pm 2.7$ & $21.8 \pm 1.4$ & $-68.3 \pm 1.7$ & $5.3 \pm 0.5$ \\
\hline S438D-S459D $(n=4)$ & $-8.4 \pm 2.6$ & $21.2 \pm 1.7$ & $-68.7 \pm 2.1$ & $5.8 \pm 1.5$ \\
\hline \multicolumn{5}{|l|}{$\mathrm{CHO}$} \\
\hline Wild type $(n=4)$ & $-1.4 \pm 2.9$ & $21.9 \pm 0.7$ & $-60 \pm 1.8$ & $4.1 \pm 0.3$ \\
\hline S438A-S459A $(n=4)$ & $-7.8 \pm 2$ & $20.5 \pm 1.3$ & $-63.5 \pm 0.7$ & $7.1 \pm 0.2$ \\
\hline S438A-S459A plus CaMKII $\Delta 316(n=5)$ & $-4 \pm 3$ & $21.7 \pm 0.3$ & $-59.5 \pm 1.7$ & $4.6 \pm 0.4$ \\
\hline \multicolumn{5}{|l|}{ Oocytes } \\
\hline Wild-type $(n=4)$ & $-18.0 \pm 2$ & $15.3 \pm 0.4$ & $-60.3 \pm 0.9$ & $3.5 \pm 0.1$ \\
\hline$S 438 A-S 459 A(n=10)$ & $-18.6 \pm 0.8$ & $15.2 \pm 0.3$ & $-61.6 \pm 0.9$ & $3.5 \pm 0.1$ \\
\hline S438D-S459D $(n=9)$ & $-17.4 \pm 0.9$ & $15.4 \pm 0.5$ & $-64.1 \pm 1.4$ & $3.5 \pm 0.1$ \\
\hline Wild type plus CaMKII $\Delta 316(n=16)$ & $-21.2 \pm 1$ & $15.2 \pm 0.1$ & $-67.2 \pm 0.6$ & $3.6 \pm 0.1$ \\
\hline
\end{tabular}


A

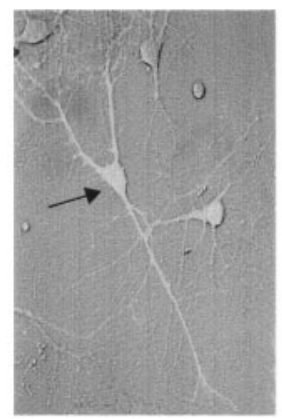

B

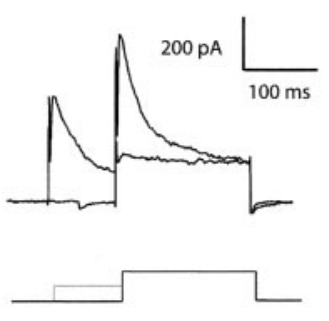

C

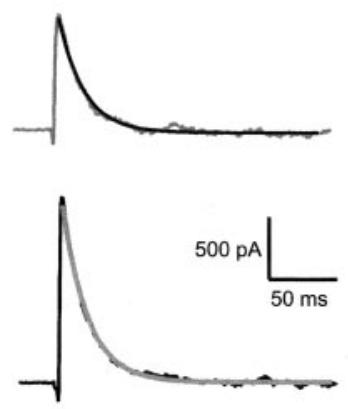

D
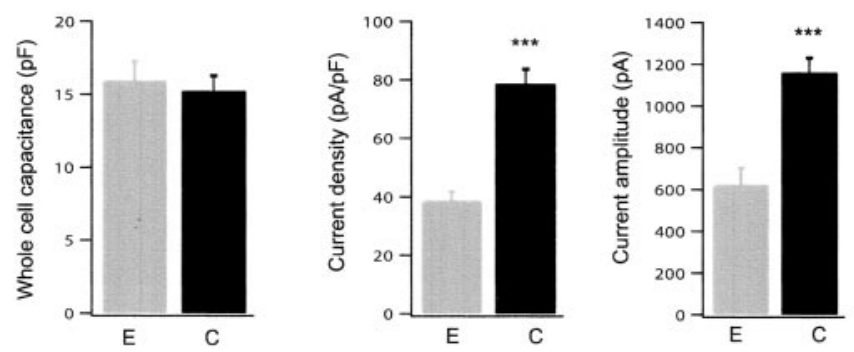

Figure 7. Active CaMKII increased A-type $\mathrm{K}^{+}$current in cultured hippocampal neurons. A, Fluorescence image of an EGFPtransfected CA1 pyramidal neuron (arrow). $B$, Schematic diagram of the prepulse voltage protocol used to isolate native $A$ currents. The prepulse was to -40 or $-20 \mathrm{mV}$. C, Representative A currents obtained from a control pyramidal neuron expressing EGFP (top) and a similar-sized pyramidal neuron expressing tCaMKII (bottom). Neurons were held at $-80 \mathrm{mV}$ and stepped to $0 \mathrm{mV}$. Decay of the A currents was fit with a single exponential. CaMKII activity increased the transient A-type $\mathrm{K}^{+}$current amplitude without a change in the inactivation time constant. $D$, Summary data for whole-cell capacitance, peak current at $0 \mathrm{mV}$, current density, and inactivation time constant for $\operatorname{EGFP}(\mathrm{E})$ and tCaMKII (C) transfected neurons. $\left({ }^{* * *} p<0.001\right)$.

$n=7$; $p<0.05)$ when $V_{\mathrm{m}}$ was held at $\sim-70 \mathrm{mV}$. Third, in response to a 1.5-2 times threshold current for $700 \mathrm{msec}$, the control neurons fired rhythmically without a decrease or with only a slight decrease in amplitude of subsequent action potentials (Fig. 8A). tCaMKII-expressing neurons, however, exhibited a disrupted firing pattern. To quantify the change in firing pattern, we measured the delay to the first action potential in response to a $700 \mathrm{msec}$ current injection. CaMKII-expressing neurons showed a significantly prolonged onset to fire the first AP $(403.6 \pm 31.3 \mathrm{pA} ; n=7)$ compared with GFP controls (230.1 \pm $19.3 \mathrm{pA} ; p<0.001$ ) (Fig. $8 A, C$ ). To test the contribution of Kv4 subunits to the prolonged onset observed in tCaMKII neurons, we used HpTx-3, a spider toxin shown to be specific for Kv4 subunits (Sanguinetti et al., 1997; Ramakers and Storm, 2002). As shown in Figure 8, when the injected currents were kept the same, the prolonged onset for APs in tCaMKII neurons was reversely shortened by application of 50-100 nм HpTx-3 from $405 \pm 19.2$ to $117.4 \pm 11.9 \mathrm{msec}(n=4 ; p<0.01)$ (Fig. $8 B, C)$. These data are consistent with our hypothesis of CaMKII increasing neuronal cell-surface Kv4 family potassium channels. Although we cannot rule out the possibility of CaMKII affecting other conductances (for example, those that contribute to the resting membrane potential), it is worth noting that neurons selectively overexpressing only Kv4.2 subunits, resulting in a subsequent increase in $I_{\mathrm{A}}$ density, display firing properties similar to what we observed in tCaMKII-transfected neurons (Shibata et al., 2000). This observation supports the hypothesis that the changes in firing properties seen with introduction of constitutively active CaMKII are mediated via increases in A-type $\mathrm{K}^{+}$currents.

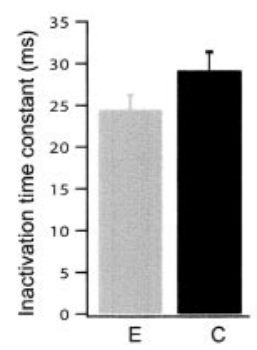

\section{Discussion}

Our findings support the idea that CaMKII regulates a novel target, the voltage-gated potassium channel $\mathrm{Kv} 4.2$, and that this interaction has the functional consequence of increasing channel expression and decreasing neuronal excitability. We began with a biochemical approach, identifying the cytoplasmic C terminus of Kv4.2 as the major site of phosphorylation and, using phosphopeptide mapping and direct amino acid sequencing, found Ser438 and Ser459 as specific phosphorylation sites. We demonstrated that CaMKII phosphorylation of Kv4.2 results in increased total cellular $\mathrm{Kv} 4.2$ protein, but it was unclear to us whether this also resulted in an increase in functional channels at the cell surface or whether the channel was merely trapped in an intracellular membrane such as the endoplasmic reticulum, Golgi body, or endosomes. Using a surface biotinylation approach and by recording whole-cell A-currents from COS cells transfected with Kv4.2 and constitutively active CaMKII, we demonstrated that a significantly increased fraction of Kv4.2 reaches the cell surface when CaMKII is present, resulting in increased peak Kv4.2 currents. This increase in peak current amplitude was unaccompanied by changes in the voltage dependence of activation and inactivation of Kv4.2. We also demonstrated that CaMKII not only potentiates Kv4.2 currents in a heterologous expression system but also increases the peak amplitudes of endogenous A-type currents in hippocampal neurons. Finally, we found that introduction of constitutively active CaMKII into hippocampal neurons causes a change in neuronal firing patterns such that the neuron has a smaller probability of firing an action potential in response to a given current input, and that the onset of action potentials is significantly delayed.

Our finding that constitutively active CaMKII leads to decreased neuronal excitability is consistent with several other studies suggesting a role for CaMKII in altering neuronal excitability. Neurons from mutant Drosophila expressing a CaMKII inhibitory peptide display increased spike frequency, increased action potential duration, and decreased stability of spike frequency coding, hallmarks of increased neuronal excitability (Yao and $\mathrm{Wu}, 2001)$. Interestingly, these neurons also display a significant decrease in A-type potassium current density. Mice with a null mutation for $\alpha$-CaMKII have increased neuronal excitability and display both spontaneous seizures and a decreased threshold for evoked seizures that involve the hippocampus (Butler et al., 1995). Similarly, CaMKII inhibition in cultured rat hippocampal neurons through an antisense oligonucleotide resulted in increased spike frequency and epileptiform activity (Churn et al., 2000). Prolonged application of the CaMKII inhibitor KN-62 to cultured embryonic mouse hippocampal neurons caused a significant decrease in A-type currents with a concomitant decrease in whole-cell capacitance, and it was suggested that this resulted from decreased CaMKII-mediated fusion of channel-bearing 
A
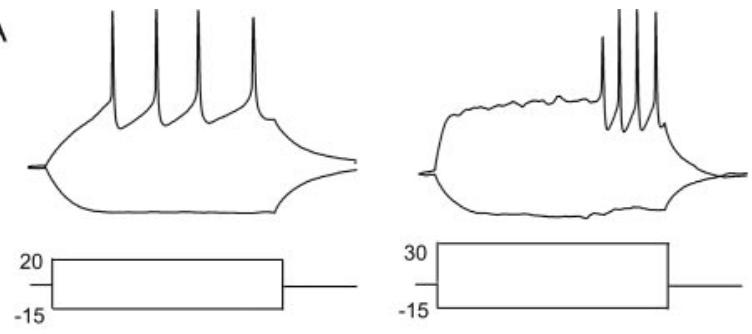

B

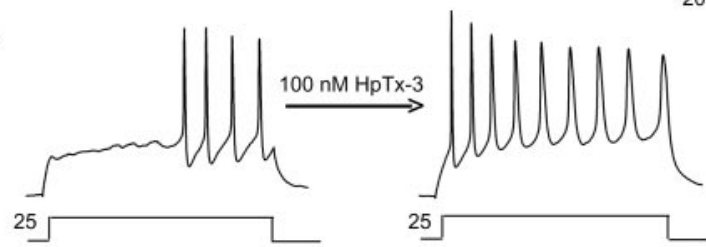

C
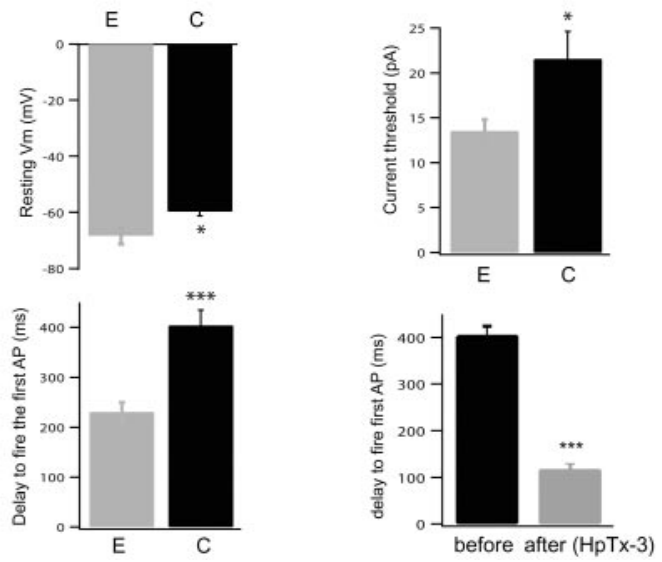

Figure 8. Active CaMKII changed the basic firing properties of hippocampal neurons. $A$, Representative traces of the action potential firing pattern of an EGFP-expressing (left) and a tCaMKII-expressing (right) pyramidal neuron in response to current injections. The amplitude of the injected current was 1.5-2 times threshold. Constitutively active CaMKII (tCaMKII) increased the time to fire the first AP under similar conditions. $B$, The prolonged onset to fire the first AP observed in the tCaMKII-expressing neuron (left) could be reversed by application of 50-100 nм HрTx-3 (right). C, Summary data for resting membrane potential, current threshold to fire APs, and delay to fire the first AP before and after HpTx-3 are shown for EGFP-expressing (E) and CaMKII-expressing (C) neurons $\left({ }^{*} p<0.05 ;{ }^{* * *} p<0.001\right)$.

vesicles with the plasmalemma (Wu et al., 1998). Clearly, from these studies and our own, CaMKII activity is required for maintaining normal cellular excitability in many systems.

Our results are distinct from accounts of CaMKII regulation of A-type currents in non-neuronal cell types as well as data suggesting a role for CaMKII in regulating the biophysical properties of other molecular mediators of A-type currents. For example, in murine colonic myocytes, inhibition of CaMKII with KN-93 or $\mathrm{KN}-62$ causes an increased rate of A-type channel inactivation and slows the recovery from inactivation with no change in peak current amplitude (Koh et al., 1999). In human atrial myocytes, KN-93 also accelerates the inactivation of the transient outward potassium current $\left(I_{\mathrm{to}}\right)$, and in this case the amplitude of the maintained component is also decreased (Tessier et al., 1999). Thus, CaMKII seems to have similar effects on Kv1.4, which also mediates an A-type current. In this vein, increasing CaMKII activity in human embryonic kidney cells expressing Kv1.4 caused a slowing of inactivation and accelerated recovery from inactivation of Kv1.4 currents (Roeper et al., 1997). Overall, the trend for CaMKII modulation of A-type currents outside the brain or en- coded by non-Kv4 molecular species has been one of altering channel biophysics, whereas CaMKII modulation of neuronal Kv4.2 increases the current amplitude. However, in all cases, CaMKII activity ultimately increases the availability of the underlying A-type channel.

Our studies do not identify the precise molecular mechanisms by which CaMKII increases Kv4.2 surface expression levels. One possibility is that CaMKII is increasing surface expression via mass action, by increasing protein half-life and increasing total cellular Kv4.2 protein. This potential mechanism is in contrast to CaMKII specifically trafficking Kv4.2 to the cell surface via phosphorylation-dependent mechanisms. Which of these is the most likely mechanism is particularly hard to ascertain, because these two possibilities are not mutually exclusive. In addition, surface membrane insertion is known to be able to stabilize proteins and increase their half-life. Thus, increased surface trafficking could result in a secondary increase in total protein in the cell. Alternatively, as mentioned above, simply increasing half-life can increase total protein and drive protein into the surface membrane. At present, each of these remains a viable alternative based on our observations.

Our findings are surprising, in that CaMKII phosphorylation of Kv4.2 and the resulting alteration in A-type current has the opposite effect of several other major kinases implicated in learning. For example, it has already been demonstrated that PKA and PKC shift the activation curve for A-type channels $\sim 15 \mathrm{mV}$ in the depolarizing direction in the distal dendrites of CA1 pyramidal neurons, a net inhibition of channel function (Hoffman and Johnston, 1998). Application of inhibitors of mitogen- and extracellular signal-regulated kinase (MEK), an upstream activator of ERK, to hippocampal pyramidal neurons results in an increased availability of A-type $\mathrm{K}^{+}$channels, indicating that ERK inhibits A-type channel function (Watanabe et al., 2002). Similarly, stimulation of $\beta$-adrenergic receptors in hippocampal slices via isoproterenol application boosts backpropagating action potential amplitude in a PKA- and ERK-MAPK-dependent manner (Yuan et al., 2002), a finding consistent with ERK inhibition of A-type channels. Furthermore, PKC suppresses Kv4.2 currents in Xenopus oocytes (Nakamura et al., 1997), and glial-derived neurotrophic factor application to dopaminergic neurons, acting through the ERK-MAPK pathway, suppresses A-type channels, leading to increased neuronal excitability (Yang et al., 2001). Thus PKA, PKC, and ERK-MAPK phosphorylation of Kv4.2 appear to result in suppression of the channel, leading to increased excitability, whereas CaMKII phosphorylation enhances channel activity through increasing surface expression. This dichotomy was the opposite of our expectation entering into these studies.

Given the multifaceted role of CaMKII in synaptic plasticity, one may wonder how a neuron might use a CaMKII-mediated upregulation of A-type current in this context. Because CaMKII has been shown to be involved in synaptic potentiation, one possibility is that CaMKII-mediated increases in Kv4.2 channel density constitute a negative feedback response, affecting the ability of synapses to undergo subsequent potentiation. Thus, CaMKII regulation of Kv4.2 insertion might be one specific mechanism contributing to a sliding threshold for LTP/long-term depression induction.

A related idea is that CaMKII-mediated upregulation of Kv4.2 could be involved in maintaining the homeostasis of neuronal firing properties (Marder and Prinz, 2002). In support of the homeostasis hypothesis, it has been demonstrated in the crab stomatogastric ganglion that several hours of depolarizing cur- 
rent pulses lead to increased peak current amplitudes of A-type potassium current (Golowasch et al., 1999). These increases were reversible after cessation of activity and were also inhibited by blocking calcium entry into cells. Our results offer a mechanism by which such homeostasis may occur: CaMKII activity can act as a readout of average $\mathrm{Ca}^{2+}$ influx and directly phosphorylate the $\mathrm{C}$ terminus of $\mathrm{Kv} 4.2$. In turn, this results in an increase in average A-currents that dampens the response of the neuron to the increased activity, until equilibrium is reached.

Finally, it has been demonstrated both electrophysiologically (Hoffman et al., 1997; Yuan et al., 2002) and anatomically (Varga et al., 2000) that there exists a gradient of A-type current and the underlying Kv4.2 $\alpha$ subunit, respectively, along hippocampal dendrites with increasing concentration away from the soma. However, the mechanisms establishing and maintaining this gradient are poorly understood. CaMKII-mediated upregulation of Kv4.2 offers a plausible mechanism for maintaining this gradient, especially in that there exists a gradient of synaptic activity along a dendrite, which could lead to a gradient of average $\mathrm{Ca}^{2+}$ influx and CaMKII activity.

Numerous long-term changes in synaptic responses and membrane excitability have been implicated in LTP. The nature of and mechanisms underlying the synaptic conductance change have been extensively investigated. In particular, increased synaptic activity involving CaMKII drives glutamate receptors into synapses to potentiate synaptic responses (Hayashi et al., 2000) and also leads to increased current flux through the channel (Barria et al., 1997; Derkach et al., 1999; Poncer et al., 2002).

However, there are often changes in excitability and EPSPspike coupling associated with neuronal plasticity, the mechanisms of which remain unknown. From the results of this study, we propose that one mechanism by which CaMKII activity may influence neuronal excitability is via regulation of potassium channels. Specifically, we propose that CaMKII phosphorylation of Kv4.2 subunits that mediate dendritic $I_{\mathrm{K}(\mathrm{A})}$ promotes surface insertion of the channel in cells. These studies are particularly exciting in that they are the first to suggest a precise molecular mechanism underlying activity-dependent long-term modification of dendritic function per se. The implication of these studies is more general, in that $\mathrm{K}^{+}$channels can be applied as an additional site beyond synaptic AMPA receptors for the regulation of ion channels by protein kinases during LTP. Together with the potentiation of synaptic conductances provided by AMPA receptor insertion, CaMKII-mediated insertion of Kv4.2 channels may provide a new dimension of plasticity that shapes the integrative properties of neurons and extends the computational capacity of neuronal networks.

In conclusion, our data have identified Kv4.2 as a novel target for CaMKII regulation with effects on channel surface expression and peak current amplitudes that are specific to the identified sites of phosphorylation on the $\mathrm{C}$ terminus of Kv4.2. CaMKIImediated increases in peak A-current amplitude have strong effects on dampening neuronal excitability in hippocampal neurons. Our findings provide a mechanism by which changes in CaMKII activity can alter neuronal excitability and also offer a plausible mechanism underlying homeostatic neuronal plasticity. These results offer a framework with which to address future questions about not only the mechanisms behind CaMKIImediated increased surface expression of Kv4.2 channels but also the consequences of calcium-triggered changes in channel expression in a time-specific and location-specific manner.

\section{References}

Adams JP, Anderson AE, Varga AW, Dineley KT, Cook RG, Pfaffinger PJ, Sweatt JD (2000) The A-type potassium channel Kv4.2 is a substrate for the mitogen-activated protein kinase ERK. J Neurochem 75:2277-2287.

An WF, Bowlby MR, Betty M, Cao J, Ling HP, Mendoza G, Hinson JW, Mattsson KI, Strassle BW, Trimmer JS, Rhodes KJ (2000) Modulation of A-type potassium channels by a family of calcium sensors. Nature 403:553-556.

Anderson AE, Adams JP, Qian Y, Cook RG, Pfaffinger PJ, Sweatt JD (2000) Kv4.2 phosphorylation by cyclic AMP-dependent protein kinase. J Biol Chem 275:5337-5346.

Barria A, Muller D, Derkach V, Griffith LC, Soderling TR (1997) Regulatory phosphorylation of AMPA-type glutamate receptors by CaM-KII during long-term potentiation. Science 276:2042-2045.

Butler LS, Silva AJ, Abeliovich A, Watanabe Y, Tonegawa S, McNamara JO (1995) Limbic epilepsy in transgenic mice carrying a $\mathrm{Ca}^{2+} /$ calmodulindependent kinase II alpha-subunit mutation. Proc Natl Acad Sci USA 92:6852-6855.

Choe S, Kreusch A, Pfaffinger PJ (1999) Towards the three-dimensional structure of voltage-gated potassium channels. Trends Biochem Sci 24:345-349.

Churn SB, Sombati S, Jakoi ER, Sievert L, DeLorenzo RJ (2000) Inhibition of calcium/calmodulin kinase II alpha subunit expression results in epileptiform activity in cultured hippocampal neurons. Proc Natl Acad Sci USA 97:5604-5609.

Derkach V, Barria A, Soderling TR (1999) $\mathrm{Ca}^{2+} /$ calmodulin-kinase II enhances channel conductance of alpha-amino-3-hydroxy-5-methyl-4isoxazolepropionate type glutamate receptors. Proc Natl Acad Sci USA 96:3269-3274.

Ehlers MD (2000) Reinsertion or degradation of AMPA receptors determined by activity-dependent endocytic sorting. Neuron 28:511-525.

Ehlers MD (2003) Activity level controls postsynaptic composition and signaling via the ubiquitin-proteasome system. Nat Neurosci 6:231-242.

Frangioni JV, Neel BG (1993) Solubilization and purification of enzymatically active glutathione $S$-transferase (pGEX) fusion proteins. Anal Biochem 210:179-187.

Giese KP, Fedorov NB, Filipkowski RK, Silva AJ (1998) Autophosphorylation at Thr286 of the alpha calcium-calmodulin kinase II in LTP and learning. Science 279:870-873.

Golowasch J, Abbott LF, Marder E (1999) Activity-dependent regulation of potassium currents in an identified neuron of the stomatogastric ganglion of the crab Cancer borealis. J Neurosci 19:RC33(1-5).

Grosse G, Draguhn A, Hohne L, Tapp R, Veh RW, Ahnert-Hilger G (2000) Expression of Kvl potassium channels in mouse hippocampal primary cultures: development and activity-dependent regulation. J Neurosci 20: $1869-1882$.

Hakes DJ, Dixon JE (1992) New vectors for high level expression of recombinant proteins in bacteria. Anal Biochem 202:293-298.

Hanson PI, Kapiloff MS, Lou LL, Rosenfeld MG, Schulman H (1989) Expression of a multifunctional $\mathrm{Ca}^{2+} /$ calmodulin-dependent protein $\mathrm{ki}$ nase and mutational analysis of its autoregulation. Neuron 3:59-70.

Hayashi Y, Shi SH, Esteban JA, Piccini A, Poncer JC, Malinow R (2000) Driving AMPA receptors into synapses by LTP and CaMKII: requirement for GluR1 and PDZ domain interaction. Science 287:2262-2267.

Hinds HL, Tonegawa S, Malinow R (1998) CAl long-term potentiation is diminished but present in hippocampal slices from alpha-CaMKII mutant mice. Learn Mem 5:344-354.

Hoffman DA, Johnston D (1998) Downregulation of transient $\mathrm{K}^{+}$channels in dendrites of hippocampal CA1 pyramidal neurons by activation of PKA and PKC. J Neurosci 18:3521-3528.

Hoffman DA, Magee JC, Colbert CM, Johnston D (1997) $\mathrm{K}^{+}$channel regulation of signal propagation in dendrites of hippocampal pyramidal neurons. Nature 387:869-875.

Holmqvist MH, Cao J, Hernandez-Pineda R, Jacobson MD, Carroll KI, Sung MA, Betty M, Ge P, Gilbride KJ, Brown ME, Jurman ME, Lawson D, Silos-Santiago I, Xie Y, Covarrubias M, Rhodes KJ, Distefano PS, An WF (2002) Elimination of fast inactivation in Kv4 A-type potassium channels by an auxiliary subunit domain. Proc Natl Acad Sci USA 99:1035-1040.

Koh SD, Perrino BA, Hatton WJ, Kenyon JL, Sanders KM (1999) Novel regulation of the A-type $\mathrm{K}^{+}$current in murine proximal colon by 
calcium-calmodulin-dependent protein kinase II. J Physiol (Lond) 517:75-84

Lledo PM, Hjelmstad GO, Mukherji S, Soderling TR, Malenka RC, Nicoll RA (1995) Calcium/calmodulin-dependent kinase II and long-term potentiation enhance synaptic transmission by the same mechanism. Proc Natl Acad Sci USA 92:11175-11179.

Malenka RC, Kauer JA, Perkel DJ, Mauk MD, Kelly PT, Nicoll RA, Waxham MN (1989) An essential role for postsynaptic calmodulin and protein kinase activity in long-term potentiation. Nature 340:554-557.

Maletic-Savatic M, Lenn NJ, Trimmer JS (1995) Differential spatiotemporal expression of $\mathrm{K}^{+}$channel polypeptides in rat hippocampal neurons developing in situ and in vitro. J Neurosci 15:3840-3851.

Malinow R, Schulman H, Tsien RW (1989) Inhibition of postsynaptic PKC or CaMKII blocks induction but not expression of LTP. Science 245:862-866

Marder E, Prinz AA (2002) Modeling stability in neuron and network function: the role of activity in homeostasis. BioEssays 24:1145-1154.

Nadal MS, Ozaita A, Amarillo Y, de Miera EV, Ma Y, Mo W, Goldberg EM, Misumi Y, Ikehara Y, Neubert TA, Rudy B (2003) The CD26-related dipeptidyl aminopeptidase-like protein DPPX is a critical component of neuronal A-type $\mathrm{K}^{+}$channels. Neuron 37:449-461.

Nakahira K, Shi G, Rhodes KJ, Trimmer JS (1996) Selective interaction of voltage-gated $\mathrm{K}^{+}$channel beta-subunits with alpha-subunits. J Biol Chem 271:7084-7089.

Nakamura TY, Coetzee WA, Vega-Saenz De Miera E, Artman M, Rudy B (1997) Modulation of Kv4 channels, key components of rat ventricular transient outward $\mathrm{K}^{+}$current, by PKC. Am J Physiol 273:H1775-H1786.

Perez-Garcia MT, Lopez-Lopez JR, Gonzalez C (1999) Kvbeta1.2 subunit coexpression in HEK293 cells confers O2 sensitivity to kv4.2 but not to Shaker channels. J Gen Physiol 113:897-907.

Pettit DL, Perlman S, Malinow R (1994) Potentiated transmission and prevention of further LTP by increased CaMKII activity in postsynaptic hippocampal slice neurons. Science 266:1881-1885.

Poncer JC, Esteban JA, Malinow R (2002) Multiple mechanisms for the potentiation of AMPA receptor-mediated transmission by $\alpha-\mathrm{Ca}^{2+}$ / calmodulin-dependent protein kinase II. J Neurosci 22:4406-4411.

Ramakers GM, Storm JF (2002) A postsynaptic transient K(+) current modulated by arachidonic acid regulates synaptic integration and threshold for LTP induction in hippocampal pyramidal cells. Proc Natl Acad Sci USA 99:10144-10149.

Roeper J, Lorra C, Pongs O (1997) Frequency-dependent inactivation of mammalian A-type $\mathrm{K}^{+}$channel KV1.4 regulated by $\mathrm{Ca}^{2+} /$ calmodulindependent protein kinase. J Neurosci 17:3379-3391.

Sanguinetti MC, Johnson JH, Hammerland LG, Kelbaugh PR, Volkmann RA, Saccomano NA, Mueller AL (1997) Heteropodatoxins: peptides isolated from spider venom that block Kv4.2 potassium channels. Mol Pharmacol 51:491-498.

Schrader LA, Anderson AE, Mayne A, Pfaffinger PJ, Sweatt JD (2002) PKA modulation of Kv4.2-encoded A-type potassium channels requires formation of a supramolecular complex. J Neurosci 22:10123-10133.

Serodio P, Rudy B (1998) Differential expression of Kv4 K ${ }^{+}$channel subunits mediating subthreshold transient $\mathrm{K}^{+}$(A-type) currents in rat brain. J Neurophysiol 79:1081-1091.

Sheng M, Tsaur M-L, Jan YN, Jan LY (1992) Subcellular segregation of two A-type $\mathrm{K}^{+}$channel proteins in rat central neurons. Neuron 9:271-284.

Shibata R, Nakahira K, Shibasaki K, Wakazono Y, Imoto K, Ikenaka K (2000) A-type $\mathrm{K}^{+}$current mediated by the $\mathrm{Kv} 4$ channel regulates the generation of action potential in developing cerebellar granule cells. J Neurosci 20: 4145-4155.

Shibata R, Misonou H, Campomanes CR, Anderson AE, Schrader LA, Doliveira LC, Carroll KI, Sweatt JD, Rhodes KJ, Trimmer JS (2003) A fundamental role for KChIPs in determining the molecular properties and trafficking of Kv4.2 potassium channels. J Biol Chem 278:36445-36454.

Silva AJ, Stevens CF, Tonegawa S, Wang Y (1992a) Deficient hippocampal long-term potentiation in alpha-calcium-calmodulin kinase II mutant mice. Science 257:201-206.

Silva AJ, Paylor R, Wehner JM, Tonegawa S (1992b) Impaired spatial learning in $\alpha$-calcium-calmodulin kinase II mutant mice. Science 257:206-211.

Song WJ, Tkatch T, Baranauskas G, Ichinohe N, Kitai ST, Surmeier DJ (1998) Somatodendritic depolarization-activated potassium currents in rat neostriatal cholinergic interneurons are predominantly of the A type and attributable to coexpression of Kv4.2 and Kv4.1 subunits. J Neurosci 18:3124-3137.

Tessier S, Karczewski P, Krause EG, Pansard Y, Acar C, Lang-Lazdunski M, Mercadier JJ, Hatem SN (1999) Regulation of the transient outward $\mathrm{K}^{+}$ current by $\mathrm{Ca}^{2+} /$ calmodulin-dependent protein kinases II in human atrial myocytes. Circ Res 85:810-819.

Tkatch T, Baranauskas G, Surmeier DJ (2000) Kv4.2 mRNA abundance and A-type $\mathrm{K}^{+}$current amplitude are linearly related in basal ganglia and basal forebrain neurons. J Neurosci 20:579-588.

Varga AW, Anderson AE, Adams JP, Vogel H, Sweatt JD (2000) Inputspecific immunolocalization of differentially phosphorylated Kv4.2 in the mouse brain. Learn Mem 7:321-332.

Veh RW, Lichtinghagen R, Sewing S, Wunder F, Grumbach IM, Pongs O (1995) Immunohistochemical localization of five members of the Kv1 channel subunits: contrasting subcellular locations and neuron-specific co-localizations in rat brain. Eur J Neurosci 7:2189-2205.

Wang JH, Kelly PT (1995) Postsynaptic injection of $\mathrm{Ca}^{2+} / \mathrm{CaM}$ induces synaptic potentiation requiring CaMKII and PKC activity. Neuron 15:443-452.

Watanabe S, Hoffman DA, Migliore M, Johnston D (2002) Dendritic K ${ }^{+}$ channels contribute to spike-timing dependent long-term potentiation in hippocampal pyramidal neurons. Proc Natl Acad Sci USA 99:8366-8371.

Wu GY, Deisseroth K, Tsien RW (2001) Spaced stimuli stabilize MAPK pathway activation and its effects on dendritic morphology. Nat Neurosci 4:151-158.

Wu RL, Butler DM, Barish ME (1998) Potassium current development and its linkage to membrane expansion during growth of cultured embryonic mouse hippocampal neurons: sensitivity to inhibitors of phosphatidylinositol 3-kinase and other protein kinases. J Neurosci 18:6261-6278.

Xia Z, Dudek H, Miranti CK, Greenberg ME (1996) Calcium influx via the NMDA receptor induces immediate early gene transcription by a MAP kinase/ERK-dependent mechanism. J Neurosci 16:5425-5436.

Yang F, Feng L, Zheng F, Johnson SW, Du J, Shen L, Wu CP, Lu B (2001) GDNF acutely modulates excitability and A-type $\mathrm{K}^{+}$channels in midbrain dopaminergic neurons. Nat Neurosci 4:1071-1078.

Yao WD, Wu CF (2001) Distinct roles of CaMKII and PKA in regulation of firing patterns and $\mathrm{K}^{+}$currents in Drosophila neurons. J Neurophysiol 85:1384-1394.

Yuan LL, Adams JP, Swank M, Sweatt JD, Johnston D (2002) Protein kinase modulation of dendritic $\mathrm{K}^{+}$channels in hippocampus involves a mitogen-activated protein kinase pathway. J Neurosci 22:4860-4868. 